\title{
Investigation on the Surface Settlement for Curved Shield Construction in Sandy Stratum with Laboratory Model Test
}

\section{Ping Xu ( $\sim$ plian127@163.com)}

Zhengzhou University https://orcid.org/0000-0001-6302-0218

\section{Danhui Xi}

Zhengzhou University

\section{Research Article}

Keywords: model test, small radius curve tunnel, surface settlement, Gaussian formula

Posted Date: April 19th, 2021

DOl: https://doi.org/10.21203/rs.3.rs-411920/v1

License: (c) (1) This work is licensed under a Creative Commons Attribution 4.0 International License. Read Full License

Version of Record: A version of this preprint was published at Geotechnical and Geological Engineering on May 12th, 2021. See the published version at https://doi.org/10.1007/s10706-021-01840-w. 


\title{
Investigation on the Surface Settlement for Curved Shield Construction in Sandy Stratum with Laboratory Model Test
}

\author{
Ping $\mathrm{Xu}^{1 *}$, Danhui $\mathrm{Xi}^{1^{*}}$ \\ ${ }^{1}$ School of Water Conservancy and Environment, Zhengzhou University, Zhengzhou 450001, P. R. China.
}

*plian127@163.com and xdh.1995@qq.com

\begin{abstract}
According to the existing practical engineering data, the settlement curve of shield tunnel with small curvature radius is obviously different from that of straight tunnel, so using Peck formula to forecast the surface settlement is not applicable. This paper describes results from a series of the laboratory test based on similarity theory carried out in sandy soil. According to the test results, the characteristics of surface settlement caused by small radius tunnel excavation are summarized, and the effects of turning radius and buried depth on the surface settlement are demonstrated. Based on Gaussian formula, a method to forecast the surface settlement caused by construction of shield tunnel with small curvature radius is developed.
\end{abstract}

Keywords: model test; small radius curve tunnel; surface settlement; Gaussian formula

\section{Introduction}

With the development of exploitation and utilization of underground space in many big cities, shield construction technology is widely used, and more and more problems arise about its application. Due to the constraints of urban planning and structures and buildings, there are many small- radius curves in the lines of city tunnels. The shield construction with small radius has the characteristics of cutterhead overbreak, shield shell pushing stratum and uneven thrust of hydraulic jack, which will cause massive ground deformation, asymmetrical surface subsidence. Therefore, the study on the ground settlement characteristics caused by shield construction with curved lines is important to ensure the safety of surrounding buildings. 
At present, the research methods of ground deformation prediction caused by shield tunnel construction mainly include theoretical analysis, empirical formula and field measurement. The Peck formula is one of the most widely used empirical equations according to field measurements (Peck 1969), and the formula was modified and developed in other studies (O'Reilly et al.1982; Attewell and Hurrell 1985; Han et al. 2007; Chen et al.2014; Fang et al.2015; Gong et al. 2018; Wang et al.2019). Many scholars also used laboratory model test to study the impact of shield construction. Wang et al. (2019) studied the settlement distribution characteristics caused by shield construction in sandy soil using homemade model test box, and proved that the shape of subsidence trough was related to the depth of ground stratum. Zhu et al. (2016) carried out a similar model test with a shield simulator to study the influence of shield construction to underground pipelines. Wang et al. (2017) studied the relationship between tunnel depth and subsidence trough parameters in sandy soil by model test, and the calculation formula of stratum subsidence with different depth was modified according to experimental data. Most of laboratory model tests on shield tunnel focused on the straight tunnel (Zhu et al. 2006; Jin and Li 2015; Sun et al. 2017; Li et al. 2018; Tao et al. 2018), while most of the research on the ground deformation rule of shield excavation in curved section was based on the field measured data and numerical simulation. Lu et al. (2018) established the prediction formula of ground settlement caused by shield excavation with different radius based on numerical simulation and field data. However, for surface settlement caused by the excavation of small radius shield tunnel, most studies on the rules are very limited, and there are no better methods to predict the surface settlement under the complicated conditions

Based on similarity theory, a homemade test device is used to simulate excavation process of shield tunnel with different turning radius and different buried depth. According to the monitoring results of the test, the characteristics of settlement caused by excavation of small radius shield tunnel are summarized, and the influences on ground settlement of turning radius and buried depth are analysed. In addition, a formula based on the Peck formula is developed to predict the surface settlement caused by curved tunnel. The test results are compared with the monitoring data of practical project to ensure the feasibility of the formula in actual projects. The rules and formula presented in this manuscript can provide a method to forecast the surface settlement caused by the 
construction of small radius shield tunnel, which will play the role of guiding construction.

\section{Design of Model Test}

\subsection{Model Test Chamber and Material}

When the buried depth is $18 \mathrm{~m}$ (2.8 times the tunnel diameter), the region of settlement mainly distributes 3 times the hole diameter on either side of the tunnel, and the region of settlement decreases with the decrease of buried depth. Therefore, for a tunnel with diameter of $6.44 \mathrm{~m}$, the lateral size is greater than $38.64 \mathrm{~m}$. So the width of the test box is greater than $0.988 \mathrm{~m}$ after the conversion. Therefore, it is determined that the length, width, and height of the test chamber are 1.2 $\mathrm{m}, 1.2 \mathrm{~m}$, and $1 \mathrm{~m}$, respectively. It is made of $10 \mathrm{~mm}$ thick tempered glass and there are two circular holes with a diameter of $167 \mathrm{~mm}$ in the centre of the anterior and posterior sides to enable the entry and exit of the shield model. The test model chamber is shown in Fig.1.

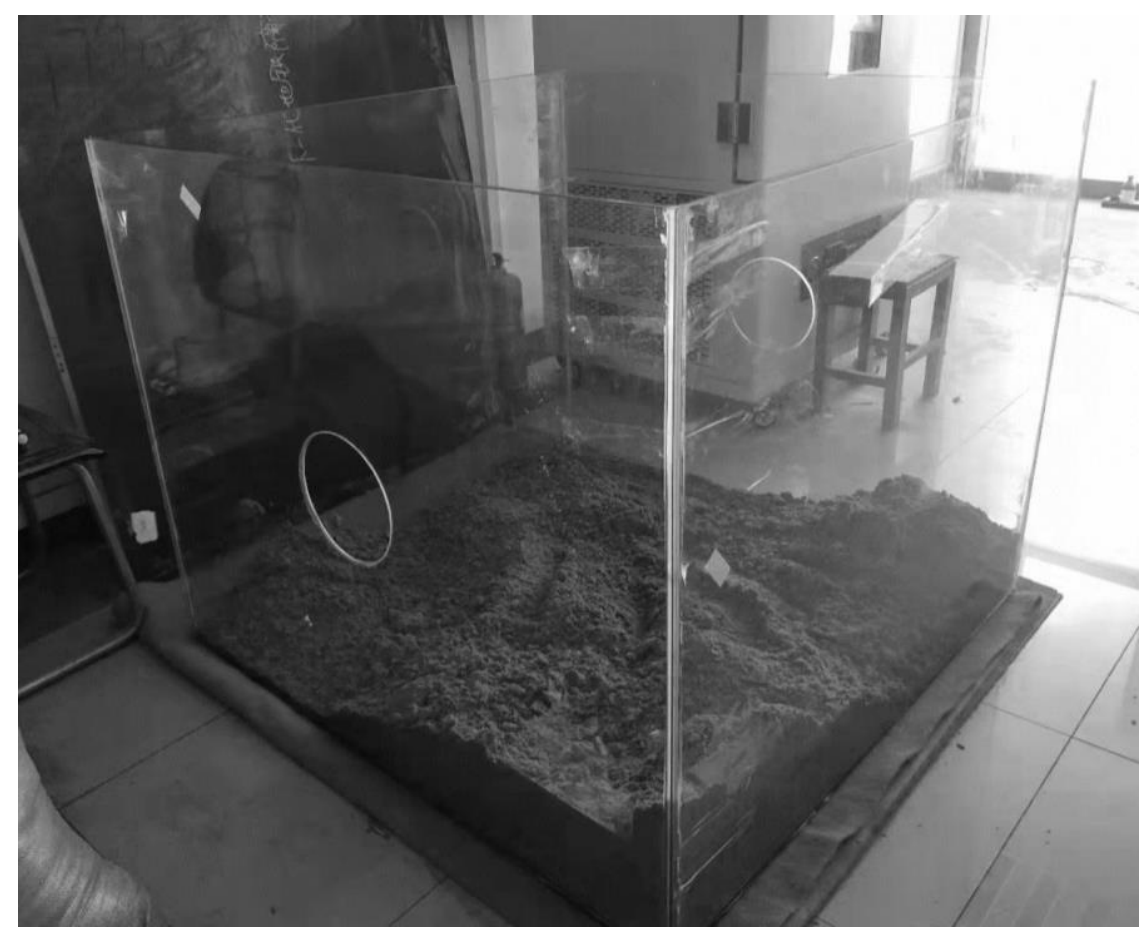

Fig.1 Model test chamber

The sand used in the test is taken from one construction site of Zhengzhou Metro line 4. Layered filling is used to ensure the homogeneity of the sand and a series of compaction test are carried out before the model test. The results show that when a layer of sand is compacted from $10 \mathrm{~cm}$ to $8 \mathrm{~cm}$, the density of the compacted sand is $1.59 \mathrm{~g} / \mathrm{cm}^{3}$. So this rule is used to fill the sandy soil into the chamber. When filling to the position of the hole, the posterior hole is sealed with glass plate, while 
the model machine is preinstall in the anterior hole with length of $10 \mathrm{~cm}$ and then continue to fill sand. The physical parameters of sandy soil are determined by soil tests, and the results are shown in Table 1.

Table 1 The physical parameters of sandy soil

\begin{tabular}{ccccc}
\hline $\begin{array}{c}\text { Elasticity } \\
\text { Modulus [MPa] }\end{array}$ & $\begin{array}{c}\text { Density } \\
{\left[\mathrm{g} / \mathrm{cm}^{3}\right]}\end{array}$ & $\begin{array}{c}\text { Internal } \\
\text { Friction Angle } \\
{\left[{ }^{\circ}\right]}\end{array}$ & Cohesion [kPa] & $\begin{array}{c}\text { Moisture } \\
\text { Content [\%] }\end{array}$ \\
\hline 25 & 1.59 & 30 & 0 & 0 \\
\hline
\end{tabular}

\subsection{Test Scheme}

In this experiment, a shield machine model is made according to the converted dimensions, as shown in Figure 2 (a). Based on the DL157 shield machine, the diameter and the length of the shield machine are $6.44 \mathrm{~m}$ and $7.98 \mathrm{~m}$, respectively, and the diameter of the segment is $6.22 \mathrm{~m}$. Because the common steel pipe sizes are specified, the steel tubes with diameter of $159 \mathrm{~mm}$ are chose to simulate the segment, which define the ratio of geometrical similitude $C_{D}$ is $1 / 39.12$. So after the conversion the diameter and the length of the model shield machine are $165 \mathrm{~mm}$ and $204 \mathrm{~mm}$, respectively, and the diameter of the segment is $159 \mathrm{~mm}$.

The shield machine is equipped with a rotating cutterhead to cut the soil. At the same time, steel tubes with different bending radius are made to simulate the segments, as shown in Figure 2 (b). The steel tubes are connected to the steel pipe, and the rear jack provides the driving force, which acts on the steel tubes. During the process of excavating, in order to control the speed of driving and reduce its impact on the data, keep taking a turn every 10 seconds to advance $5 \mathrm{~mm}$. In order to prevent too much soil pressure in the tube, the sand should be dug out manually.

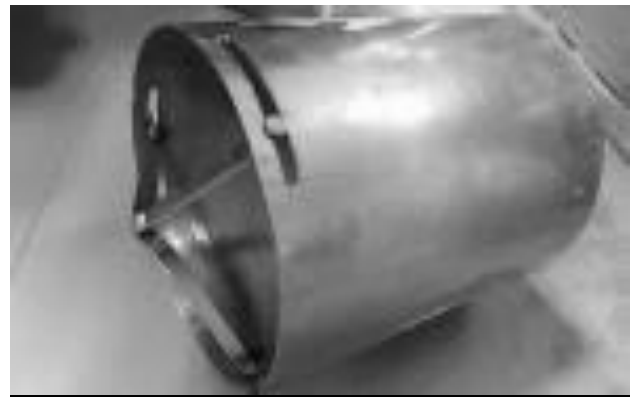

(a) Shield machine model

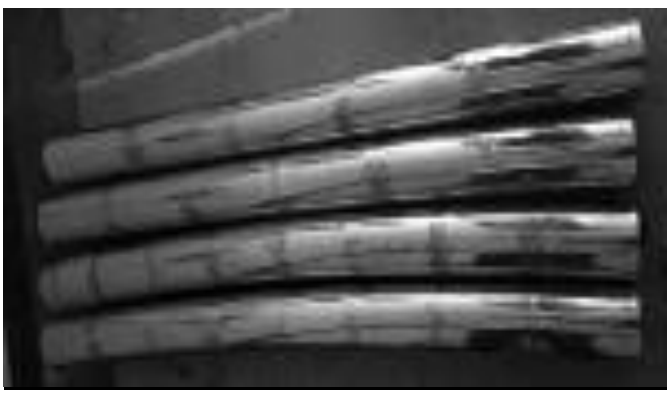

(b) Segment model

Fig.2 Shield machine and segment models 
In this test, there are eight conditions, the buried depth is expressed as the ratio of buried depth to tunnel diameter, and the curvature radius is converted to the actual radius, as Table 2 shown.

Table 2 Test conditions

\begin{tabular}{ccc}
\hline Kind & $\begin{array}{c}\text { Ratio of buried depth to } \\
\text { tunnel diameter }\left(z_{0} / D\right)\end{array}$ & $\begin{array}{c}\text { Turning radius } \\
{[\mathrm{m}]}\end{array}$ \\
\hline Condition 1 & 1 & 250 \\
Condition 2 & 1 & 300 \\
Condition 3 & 1 & 500 \\
Condition 4 & 1 & 800 \\
Condition 5 & 1.5 & 250 \\
Condition 6 & 1.5 & 800 \\
Condition 7 & 2 & 250 \\
Condition 8 & 2 & 800 \\
\hline
\end{tabular}

\subsection{Arrangement of Monitoring Points}

There are 11 monitoring points are designed in the range of 3 times the tunnel diameter from the central axis. Moreover, the cross-section, which is $40 \mathrm{~cm}$ away from the tunnel portal, is selected as the measurement section. Because the tunnel line is curved, the axis of the test box does not coincide with the tunnel axis, the deviation of tunnel axis should be taken into account. The arrangements of monitoring points are shown in Figure 3. Dial gauges and gaskets are used to finish measurement, as shown in Figure 4. And measurement range and accuracy of the dial gauges is $10 \mathrm{~mm}$ and $0.01 \mathrm{~mm}$, respectively.

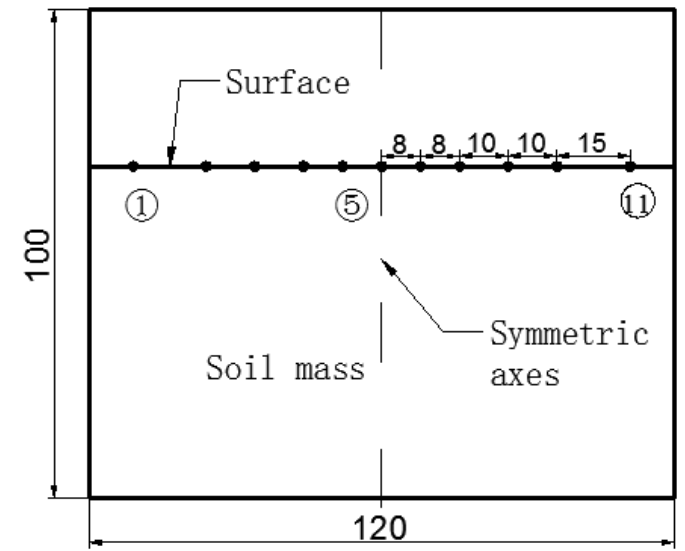

(a) Front view

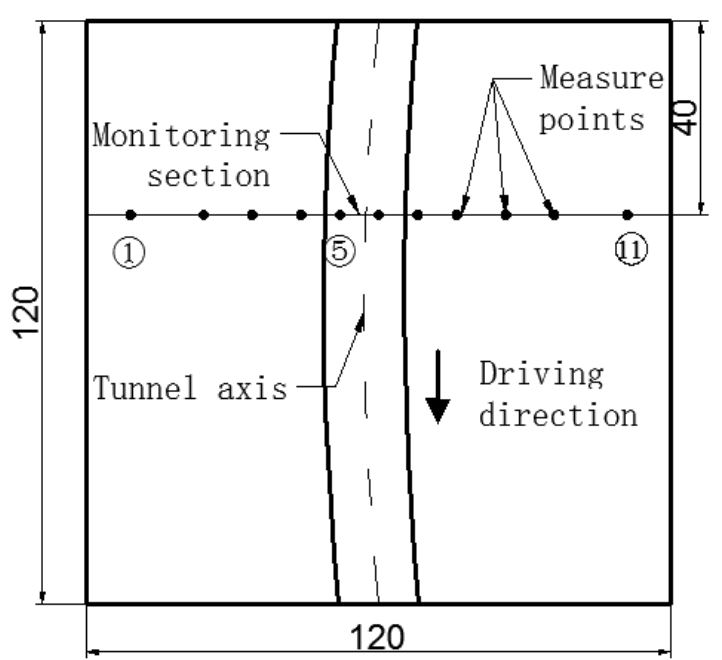

(b) Top view

Fig.3 Sketch of observation points arrangement (unit: $\mathrm{cm}$ ) 


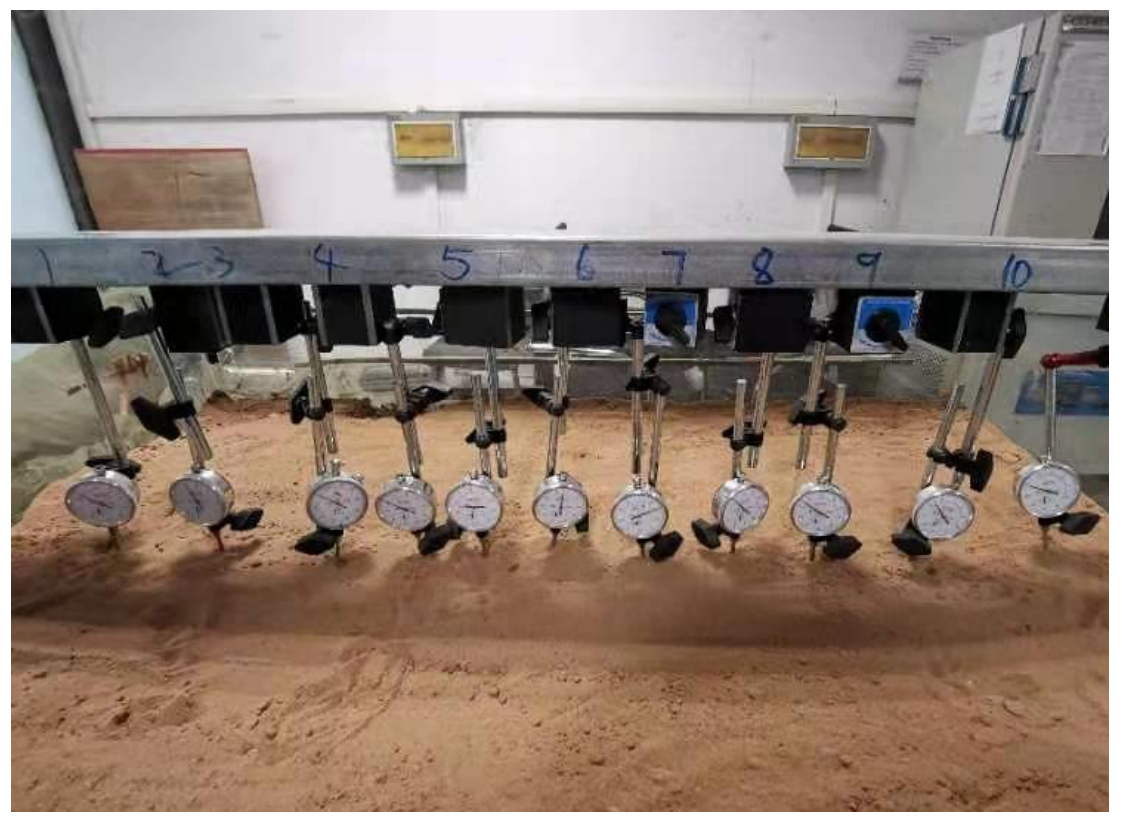

Fig.4 Installation of dial gauges.

\section{Test Results and Analysis}

The turning radius can affect the position of the tunnel axis, so when the centre of the tunnel is taken as the origin of the $\mathrm{X}$-axis, the practical coordinate of each measure points are calculated according to geometry, they are shown in Table 3.

Table 3 Coordinates of observation points with different turning radius

\begin{tabular}{ccccc}
\hline $\begin{array}{c}\text { Turning radius } \\
{[\mathrm{m}]}\end{array}$ & 250 & 300 & 500 & 800 \\
\hline Point 1 & -19.214 & -19.337 & -19.574 & -19.720 \\
Point 2 & -13.344 & -13.467 & -13.704 & -13.850 \\
Point 3 & -9.434 & -9.557 & -9.794 & -9.940 \\
Point 4 & -5.524 & -5.647 & -5.884 & -6.030 \\
Point 5 & -2.394 & -2.517 & -2.754 & -2.900 \\
Point 6 & 0.736 & 0.613 & 0.376 & 0.230 \\
Point 7 & 3.866 & 3.743 & 3.506 & 3.360 \\
Point 8 & 6.996 & 6.873 & 6.636 & 6.490 \\
Point 9 & 10.906 & 10.783 & 10.546 & 10.400 \\
Point 10 & 14.816 & 14.693 & 14.456 & 14.310 \\
Point 11 & 20.686 & 20.563 & 20.326 & 20.180 \\
\hline
\end{tabular}

\subsection{Influence of Turning Radius on Surface Settlement}

In order to explore the influence of turning radius on surface settlement, the stable monitoring data of conditions 1, 2, 3 and 4 are compared in the test results, and the results are shown in Figure 5. 


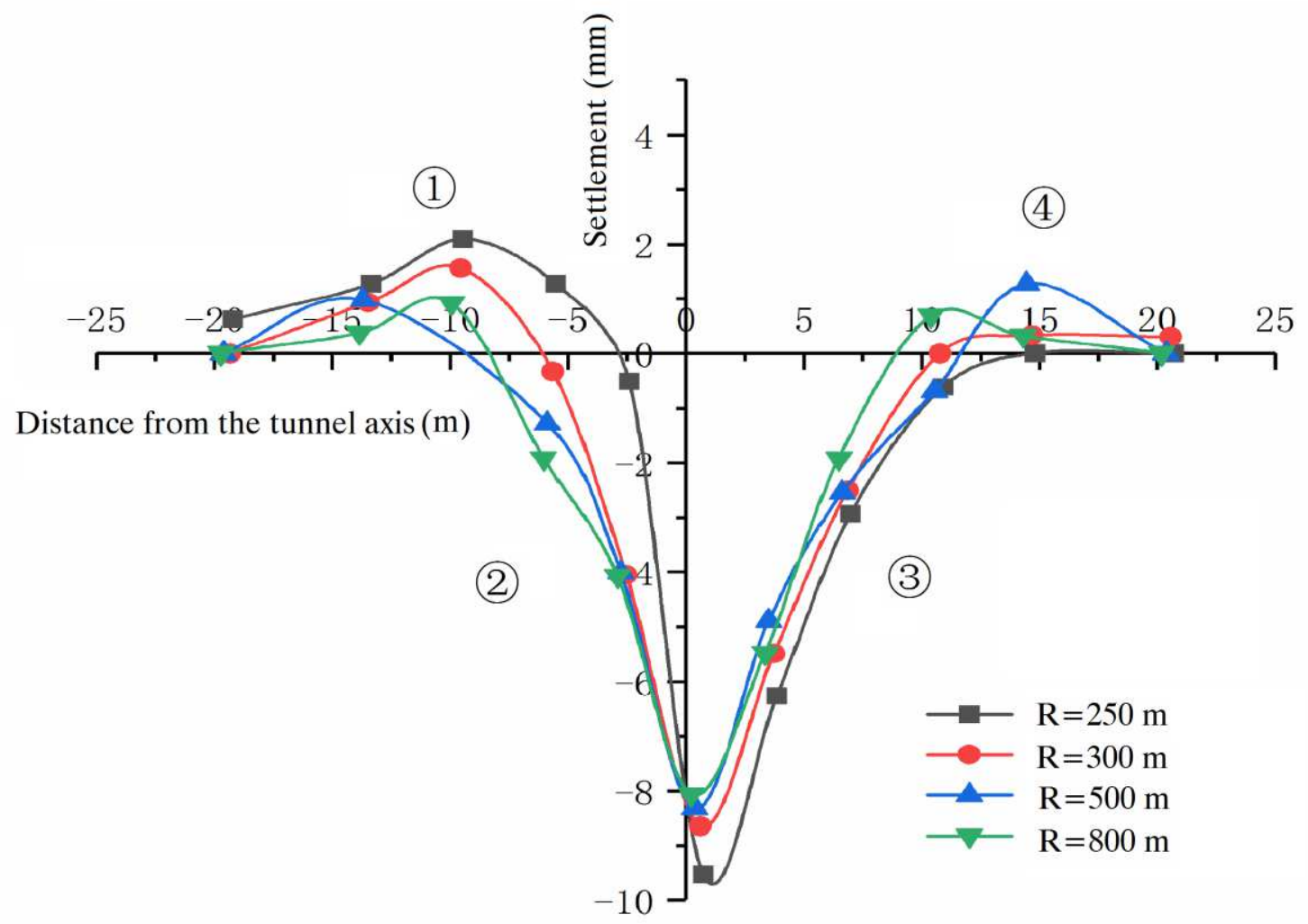

Fig.5 Test results of surface settlement with different turning radius (The $\mathrm{R}$ means the turning radius)

According to Figure 5, there are four parts of the surface displacement caused by the excavation of shield tunnel with small radius: (1)ground heave of the left side, (2)settlement of the left side, (3) ground heave of the right side and (4)settlement of the right side. The approximate ranges and secant slopes of the four parts are shown in Table 4. 
Table 4 Characteristics statistical table of test curve

\begin{tabular}{|c|c|c|c|c|c|c|c|c|}
\hline \multirow{3}{*}{ Portion } & \multicolumn{8}{|c|}{ Turning radius [m] } \\
\hline & \multicolumn{2}{|c|}{250} & \multicolumn{2}{|c|}{300} & \multicolumn{2}{|c|}{500} & \multicolumn{2}{|c|}{800} \\
\hline & Range & Slope & Range & Slope & Range & Slope & Range & Slope \\
\hline (1) & 16.4 & - & 13 & - & 10.6 & - & 11.4 & - \\
\hline (2) & 3.6 & -2.88 & 6.8 & -1.33 & 9.8 & -1.13 & 8.6 & -0.98 \\
\hline (3) & 14 & 1.05 & 10.2 & 0.98 & 11.3 & 0.92 & 8.7 & 0.98 \\
\hline (4) & - & - & 10 & - & 8.3 & - & 11.3 & - \\
\hline & & & & & ${ }^{(2)} \mathrm{S}$ & 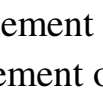 & , & $\begin{array}{l}\text { de } \\
\text { ide }\end{array}$ \\
\hline
\end{tabular}

The following conclusions can be drawn from Fig.5 and Table 3:

(1) When the turning radius is small, ground heave on the outer side of the tunnel (left side of coordinate axis) is obvious, and the left curve is steeper than the right curve. Therefore, the settlement curve is asymmetrical, the point of maximum settlement is not right above the tunnel axis, but move to the inside of the tunnels, and the smaller the turning radius, the greater the offset. When the turning radius is $800 \mathrm{~m}$, the surface displacement on both sides of the tunnel is generally symmetrical, which is the same with the prediction of Peck formula.

(2) The range of ground heave increase with the decrease of turning radius. With the increase of distance from tunnel axis, the value of uplift first increases and then decreases, and the point of peak value is at $2 / 3$ among the range. The smaller the turning radius, the larger the maximum uplift value. Accordingly, the range of the settlement on the left side decreases with the reduction of turning radius. The effect of turning radius on the inner side is not as obvious as that on the outer side. When turning radius is too small, no uplift occurs on the inner side.

(3) The change rate of surface settlement on the outside becomes larger when the turning radius becomes smaller. When the turning radius is $250 \mathrm{~m}$, the absolute value of the slope of settlement on the outside reaches 2.88 , which increases about $117 \%$ compared with that of turning radius $300 \mathrm{~m}$, while the change rate of settlement curve on the inside does not change much.

It can be inferred from the above phenomenon that for shield tunnel construction, the effect of turning radius on surface settlement of the outer side is much greater than that of the inner side. Because when the shield tunnel with small radius is excavated, there is an angle between the driving route and the direction of the thrust from the jack, which can result in horizontal component force, and it pushes the shield body to squeeze the outer soil. So that the ground surface of left side uplift 
and the settlement change rate increases.

\subsection{Piecewise Fitting with Gaussian Curve}

From the study in the previous section, it is found that surface settlement curve caused by the small-radius shield excavation is no longer symmetrical, and the Peck formula is no longer applicable. A method of piecewise fitting with Gaussian curve is used to fit the settlement curve of the smallradius shield in this paper as follows:

$$
\left.\begin{array}{c}
y=y_{1}+\frac{A_{1}}{w_{1} \sqrt{\frac{\pi}{2}}} e^{-\frac{\left(x-x_{c}\right)^{2}}{2 w_{1}^{2}}}\left(x<x_{c}\right) \\
y=y_{2}+\frac{A_{2}}{w_{2} \sqrt{\frac{\pi}{2}}} e^{-\frac{\left(x-x_{c}\right)^{2}}{2 w_{2}^{2}}}\left(x>x_{c}\right)
\end{array}\right\}
$$

Where, $y$ is the value of surface settlement; $x$ is the distance from the tunnel axis; $y_{1} 、 y_{2}$ are the convergence values of the fitted curve on the left and right sides, respectively; $w_{1} 、 w_{2}$ are the width coefficient of the surface settlement trough on the left and right sides, respectively; A1、A2 are the amplitude of both sides respectively; $x_{c}$ is the distance from the point of the maximum settlement to the tunnel axis.

Because of the inside overbreak of the shield tunnel with a small radius, the maximum value of cross-sectional settlement is not at the point of the tunnel axis, but move to the inner side of the tunnel line. According to Sigl O and Atzl G (1999), the effect of the amount of overbreak is considered, as shown in Figure 6. 


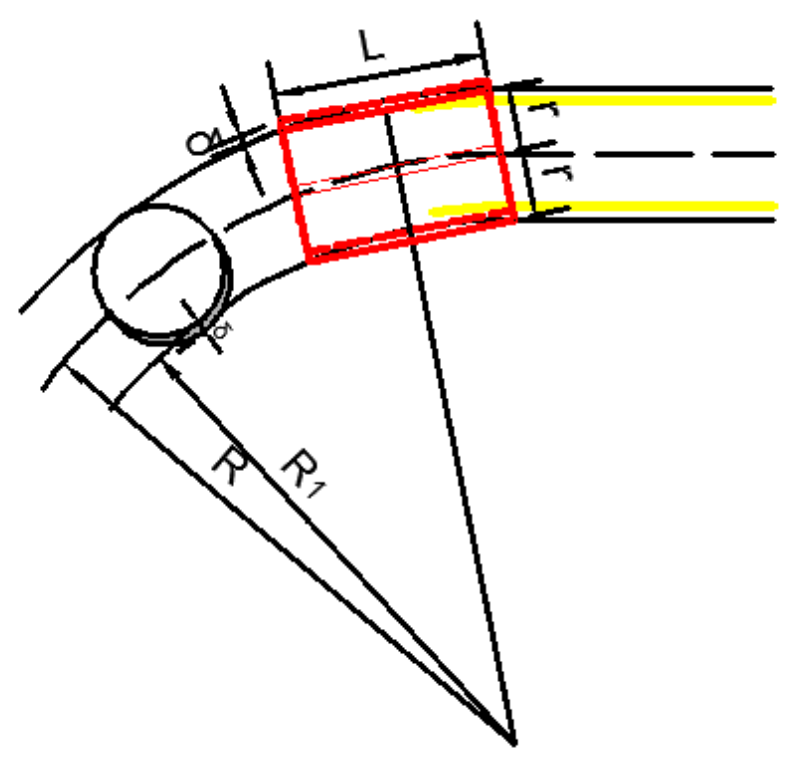

Fig.6 Situation for curvature loss

The formula for calculating the width of overbreak $\delta$ is shown as the equation (2) (Sigl and Atzl 1999).

$$
\delta=\sqrt{(R+r)^{2}+\left(\frac{L}{2}\right)^{2}}-(R+r)
$$

While $\delta$ is the width of overbreak, $R$ is the turning radius of the runnel, $r$ is the radius of the tunnel, which is $3.22 \mathrm{~m}$ in this paper, and $L$ is the length of the shield machine, which is $7.98 \mathrm{~m}$.

Define the point that $x=\delta$ as the dividing point, in other words, $x_{c}=\delta$. The calculation results are shown in Table 5.

Table 5 Settlement offset with different turning radius

\begin{tabular}{ccccc}
\hline Turning radium $[\mathrm{m}]$ & 250 & 300 & 500 & 800 \\
\hline Offset $(\delta)[\mathrm{m}]$ & 0.031 & 0.026 & 0.016 & 0.010 \\
\hline
\end{tabular}

The fitting results are shown in Figure 7. 


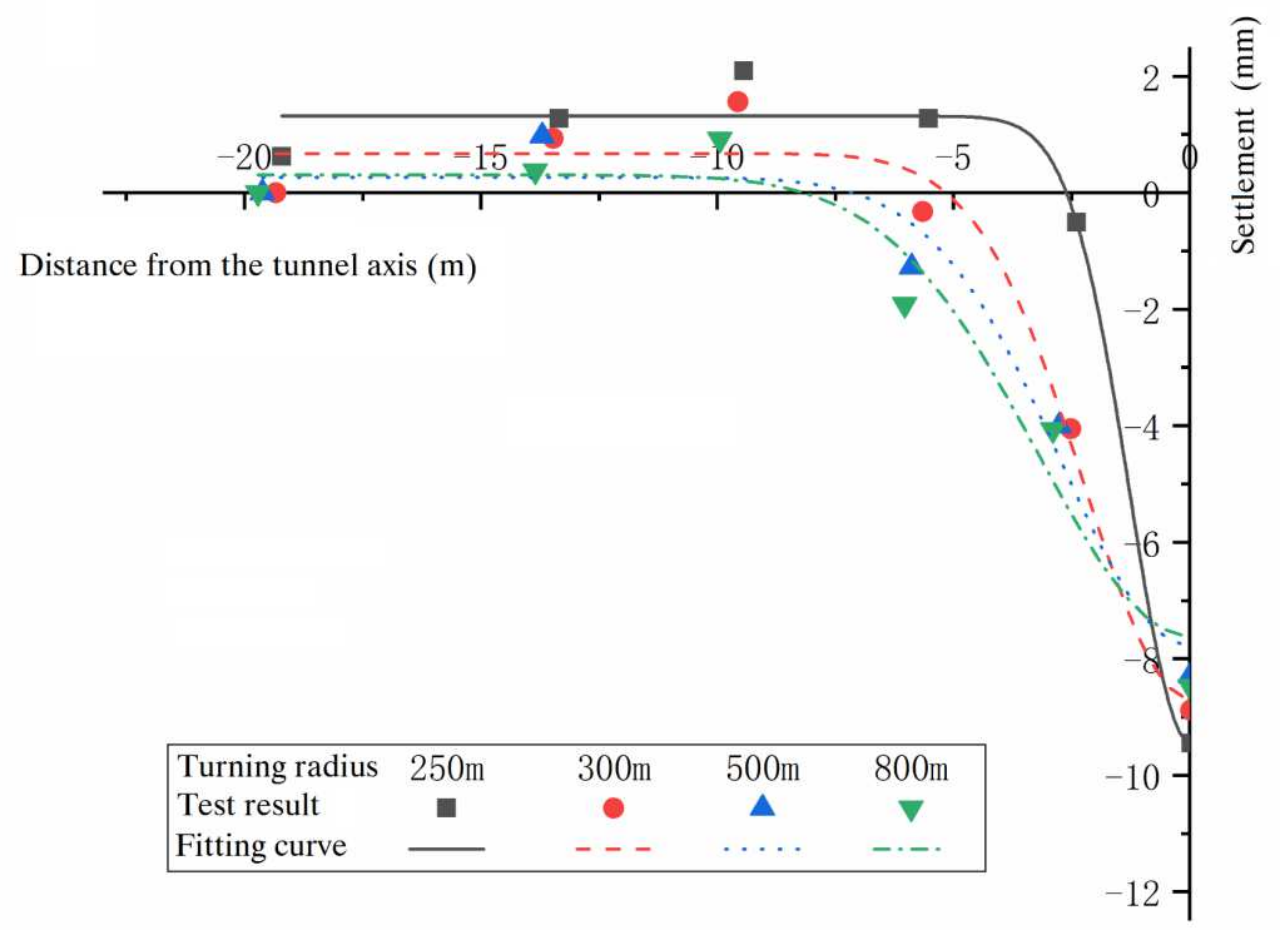

(a) Fitting curves of left side

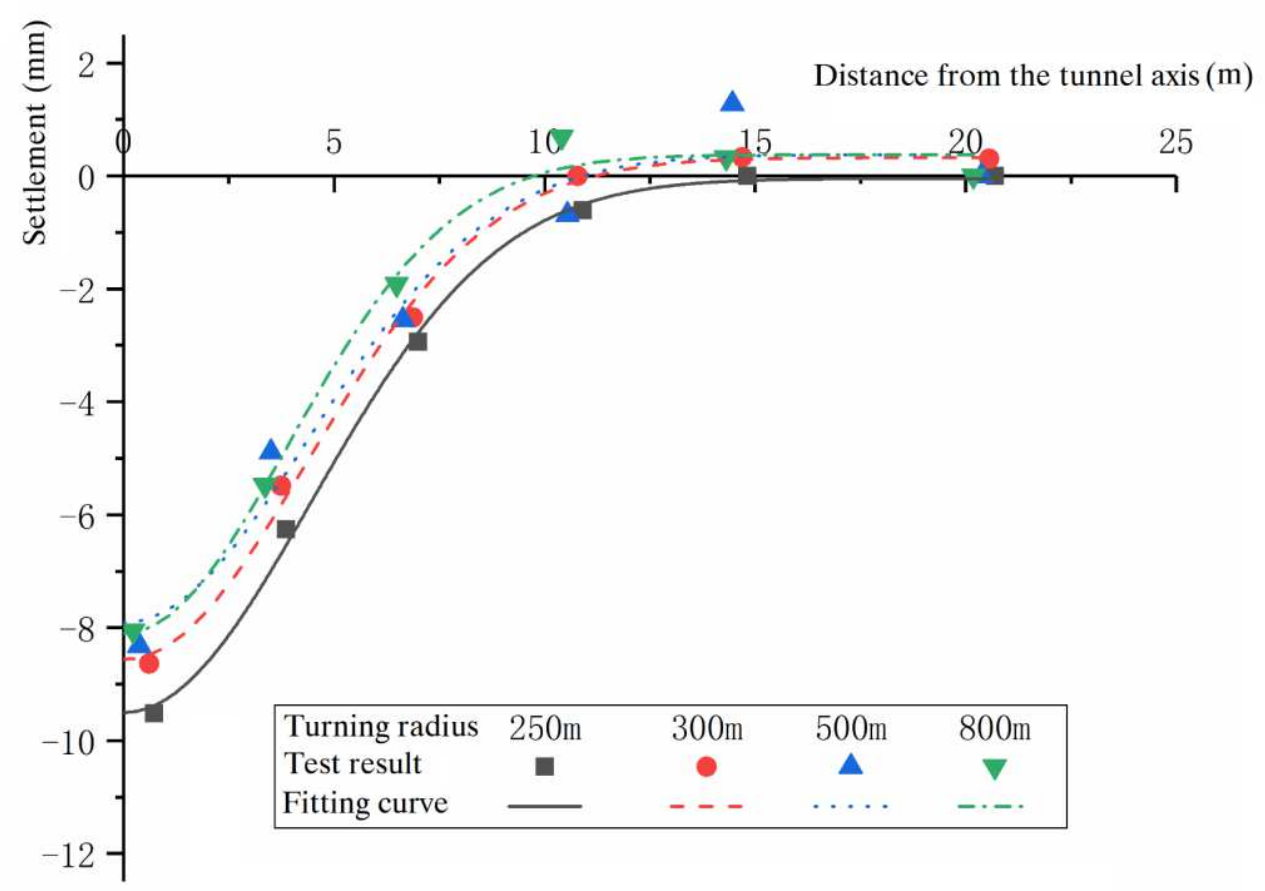

(b) Fitting curves of right side

Fig.7 Piecewise fitted curves by Gaussian equation

From Figure 7, it can be seen that the segmented curves can fit well to the test results in the part of settlement (part 2 and 3). For the part of uplift (part 1 and 4), the average value of the uplift can 
also be roughly inferred by the fitted curves.

The parameters of the fitted Gaussian curve: maximum settlement $S_{\max }$, width coefficient of the settlement trough on the left side $i_{1}$, width coefficient of the settlement trough on the right side $i_{2}$, and offset of the settlement trough $x_{c}$ are listed in Table 6.

Table 6 Parameters of fitting carves

\begin{tabular}{ccccc}
\hline Turning radium $[\mathrm{m}]$ & $S_{\max }[\mathrm{mm}]$ & $i_{1}[\mathrm{~m}]$ & $i_{2}[\mathrm{~m}]$ & $x_{c}[\mathrm{~m}]$ \\
\hline 250 & 9.452 & 1.287 & 4.422 & 0.031 \\
300 & 8.881 & 2.260 & 4.335 & 0.026 \\
500 & 8.284 & 2.744 & 4.381 & 0.016 \\
800 & 8.471 & 3.210 & 3.898 & 0.010 \\
\hline
\end{tabular}

It can be inferred from Table 6 that shield tunnel construction with small radius will intensify the settlement. And the width coefficient of the settlement trough on the left side will increase with the decrease of the turning radius, while the width coefficient of inner side does not change a lot. In order to analyse the effect of turning radius on settlement trough clearly, the data in Table 6 are marked in Figure 8 .

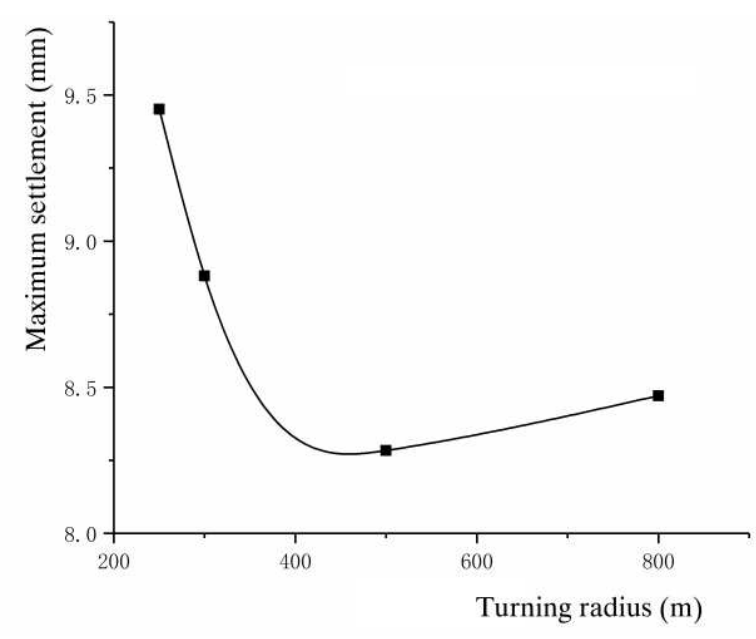

(a) Maximum settlement

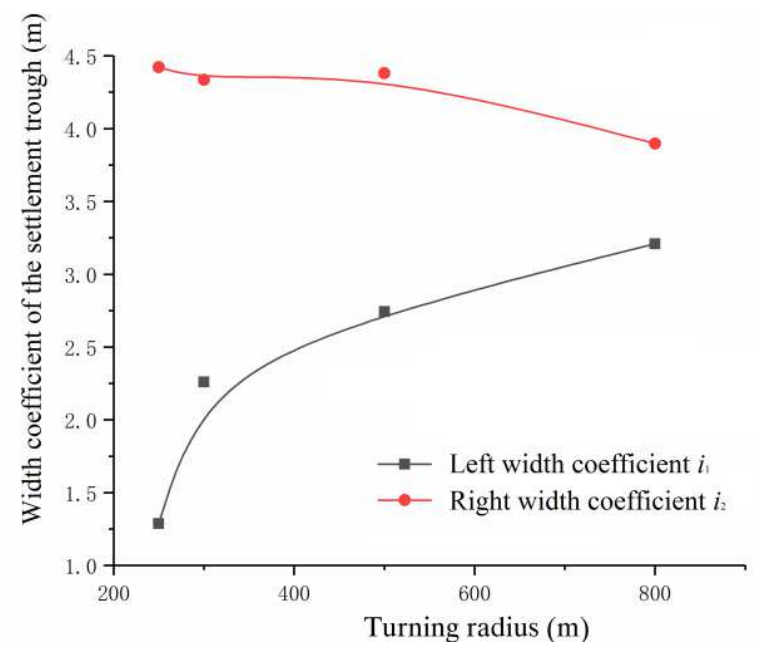

(b) Width coefficient of the settlement trough

Fig.8 Relation curves between settlement curve parameters and turning radius

From Figure 7 and Figure 8, it can be seen that:

(1) For the condition of the excavation of curve shield tunnel, the shape of the settlement trough can be described by a piecewise Gaussian curve, and it is reasonable to use the width of overbreak as the offset of the peak point. The peak of the ground heave is about twice the result of the fitted curve, so the ground heave can be predicted by interpolating according to the uplift range and peak analysed 
in Section 3.2 above.

(2) The width coefficient of the settlement trough on the left side $i_{1}$ increases exponentially with the increase of turning radius. The width coefficient of the right side $i_{2}$ decreases with the increase of the turning radius, but the change is not significant compared with $i_{1}$, and the value of $i_{1}$ and $i_{2}$ gradually approach one another with the increase of turning radius, which means that the settlement curve gradually becomes symmetry.

(3) The maximum settlement $S_{\max }$ increases exponentially with the decrease of the turning radius. WhenR $\leq 350 \mathrm{~m}$, the growth rate of settlement is very fast, and when $R \geq 400 \mathrm{~m}$, the value of $S_{\max }$ stabilizes at $8.3 \mathrm{~mm}$, as for $\mathrm{R}=250 \mathrm{~m}$, the maximum settlement increases by $13.9 \%$ compared with the stable value.

\subsection{Effect of Burial Depth on Surface Settlement for Curved Tunnel}

Treat conditions 1,5 and 7 in Table 2 as group $1(\mathrm{R}=250 \mathrm{~m})$ and conditions 4,6 and 8 as group $2(\mathrm{R}=800 \mathrm{~m})$. Using the method of piecewise Gaussian curve to fit the shape of settlement trough, and mark the test results and fitting curves in Figure 9, where $z_{0} / D$ is the ratio of tunnel burial depth to tunnel diameter.

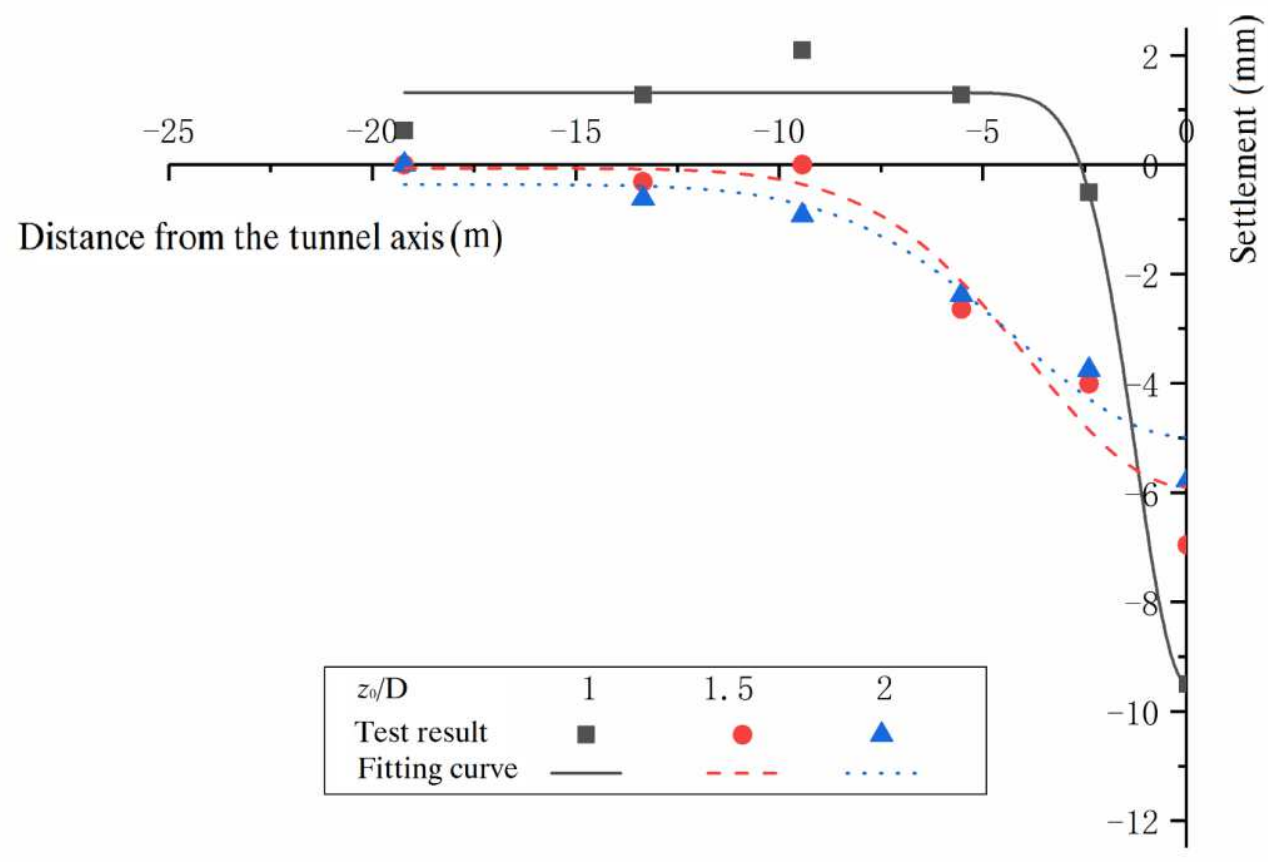

(a) Left surface settlement curve of group 1 


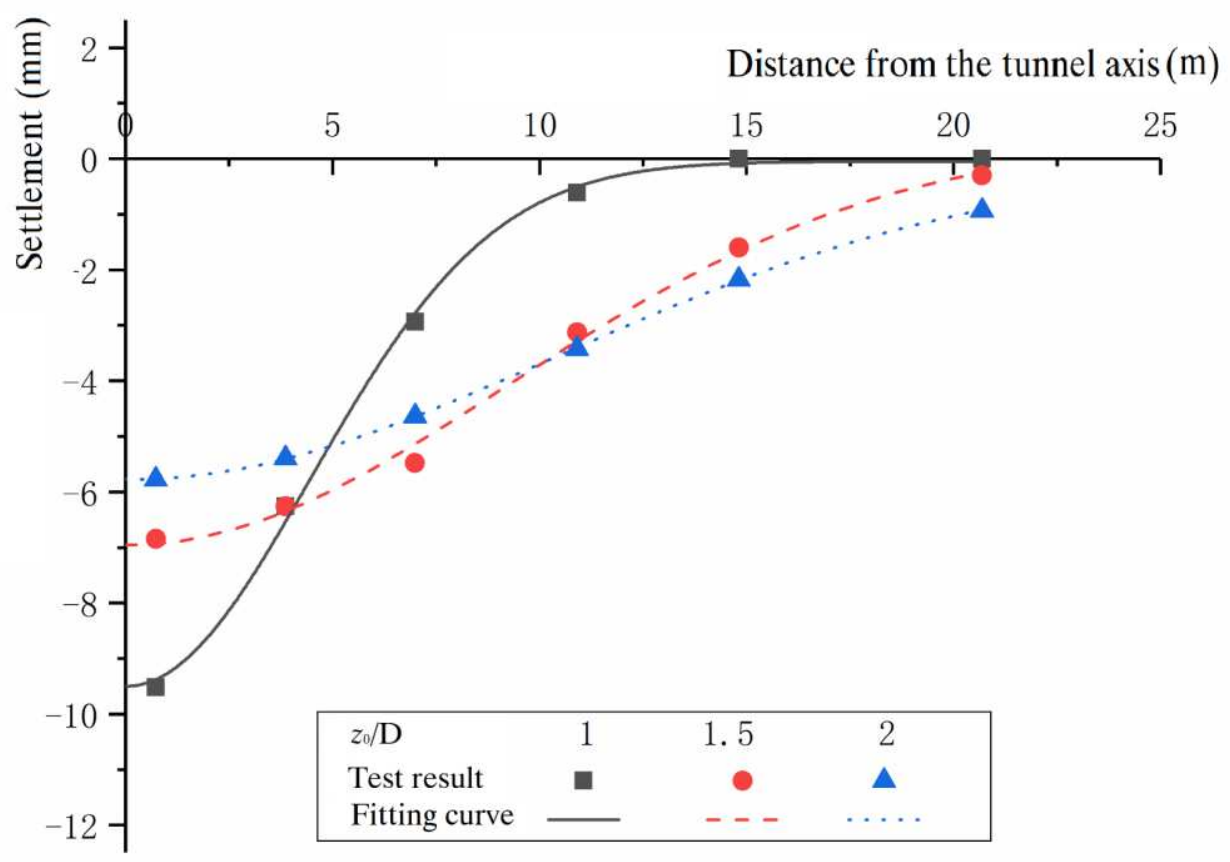

(b) Right surface settlement curve of group 1

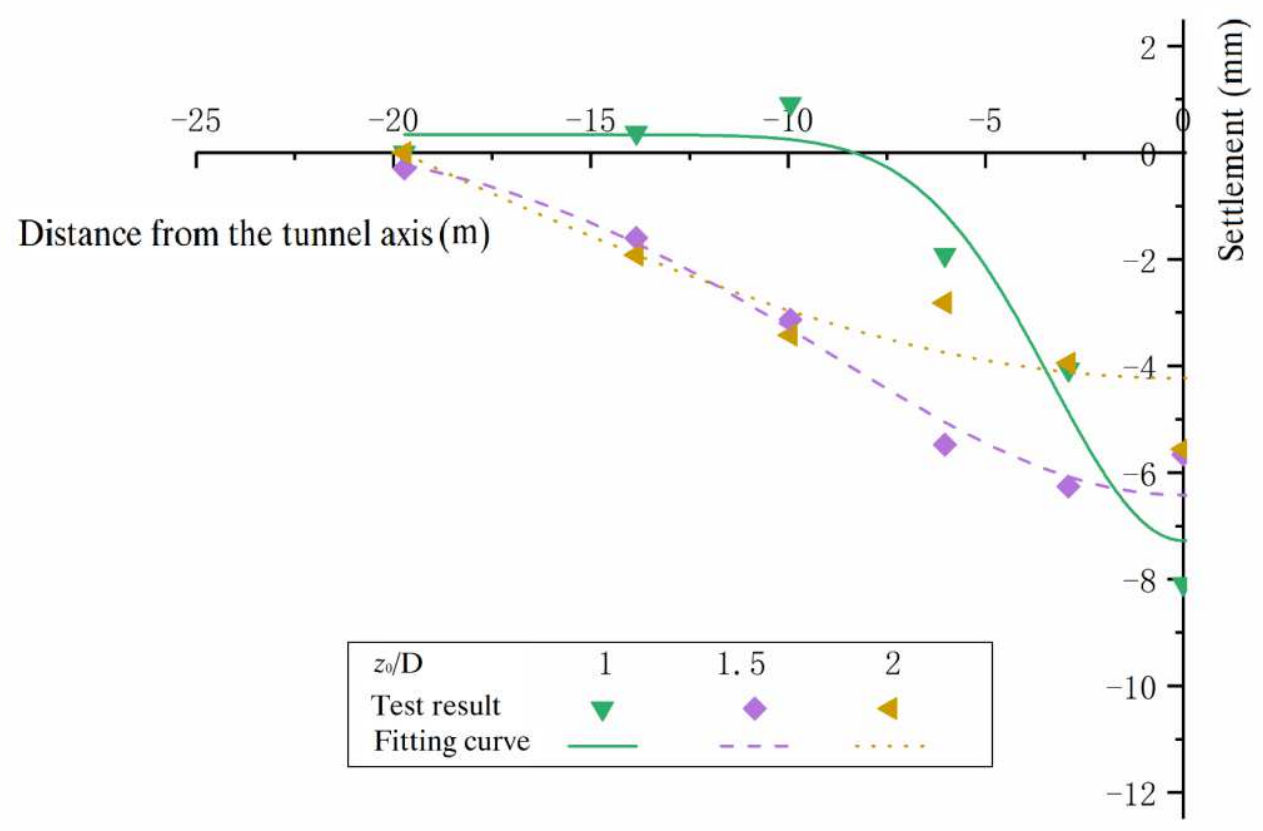

(c) Left surface settlement curve of group 2 


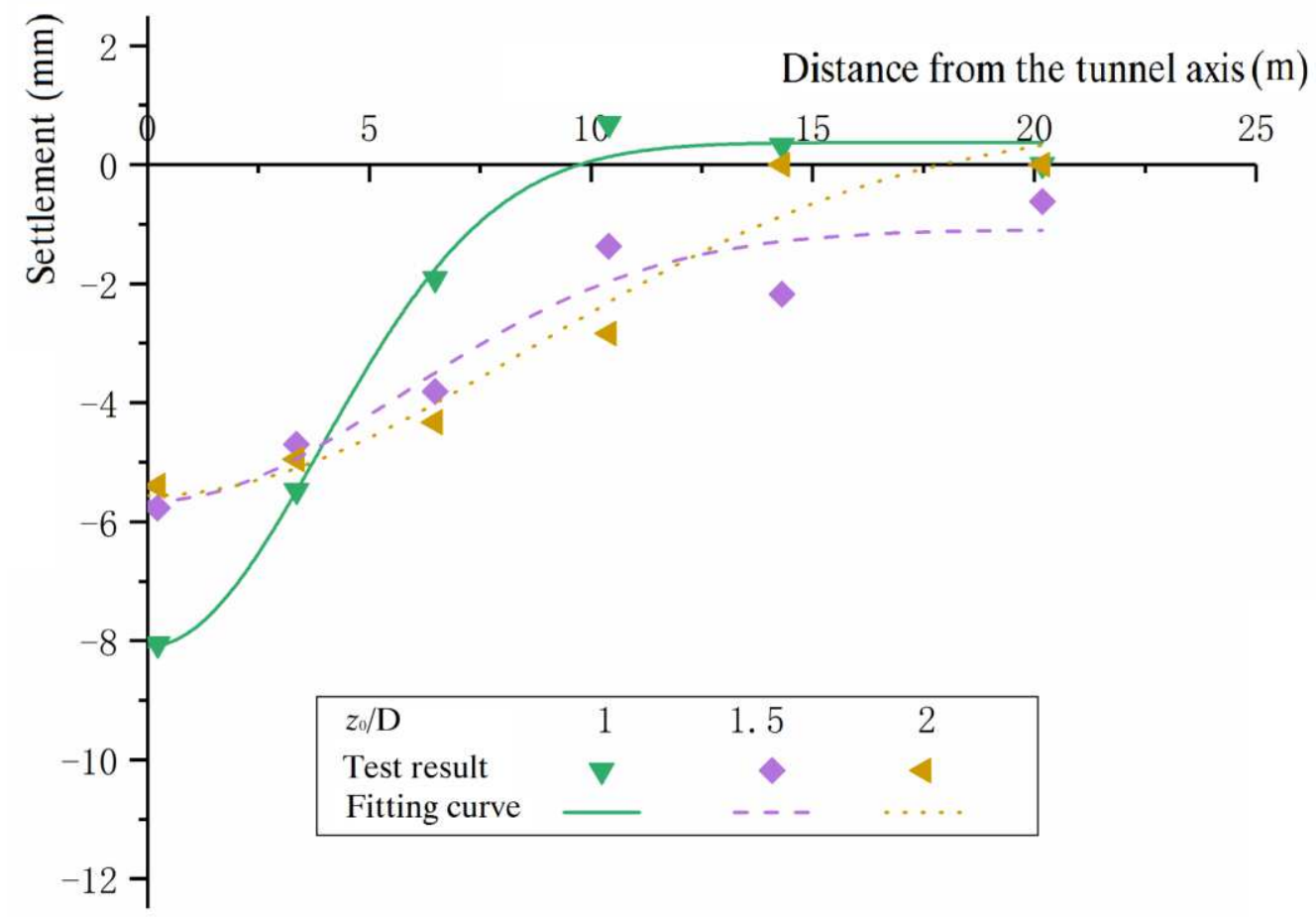

(d) Right surface settlement curve of group 2

Fig.9 Piecewise fitted curves Gaussian equation of surface settlement with different buried depth

The parameters of surface settlement curves of tunnels with different buried depths are listed in the Table 7.

Table 7 Fitting curves parameters of surface settlement with different buried depth

\begin{tabular}{ccccccc}
\hline \multirow{2}{*}{$z_{0} / D$} & \multicolumn{3}{c}{$\mathrm{R}=250 \mathrm{~m}$} & \multicolumn{3}{c}{$\mathrm{R}=800 \mathrm{~m}$} \\
& $S_{\max }[\mathrm{mm}]$ & $i_{1}[\mathrm{~m}]$ & $i_{2}[\mathrm{~m}]$ & $S_{\max }[\mathrm{mm}]$ & $i_{1}[\mathrm{~m}]$ & $i_{2}[\mathrm{~m}]$ \\
\hline 1.0 & 9.497 & 1.285 & 4.422 & 7.686 & 3.342 & 3.898 \\
1.5 & 6.425 & 3.860 & 9.192 & 6.042 & 5.026 & 5.711 \\
2.0 & 5.380 & 4.224 & 10.372 & 4.893 & 8.460 & 8.625 \\
\hline
\end{tabular}

The following laws can be seen from Figure 9 and Table 7:

(1) It is proved again that a piecewise Gaussian curve is practicable to fit the shape of the settlement trough, especially the settlement part.

(2) Whatever the turning radius is, the laws of the parameter variation are the same. The ground settlement caused by excavation decreases with the increase of the tunnel burial depth, while the width of settlement trough increases.

\section{Feasibility in Actual Project}

There is a horizontal curve section with turning radium of $250 \mathrm{~m}$ in Hexi entrance and exit line 
of Zhengzhou Metro Line 4. Moreover, $z_{0} / D$ of this section is about 1.0. In order to discuss the feasibility of the piecewise Gaussian curve in actual project, monitoring data of Zhengzhou Metro Line 4 are collect and analysed.

For actual projects, there are copy cutters on the edge of the cutting disk. When the tunnel axis is curving, the copy cutter will extend to break surrounding soil. Therefore, the value of overbreak depends on the elongation of the copy cutters. According to the data collected, the elongation of this section is $100 \mathrm{~mm}$, so $x_{c}$ of the settlement trough is $100 \mathrm{~mm}$.

Draw the surface monitoring data of a typical section and fitting curve in Figure 10.

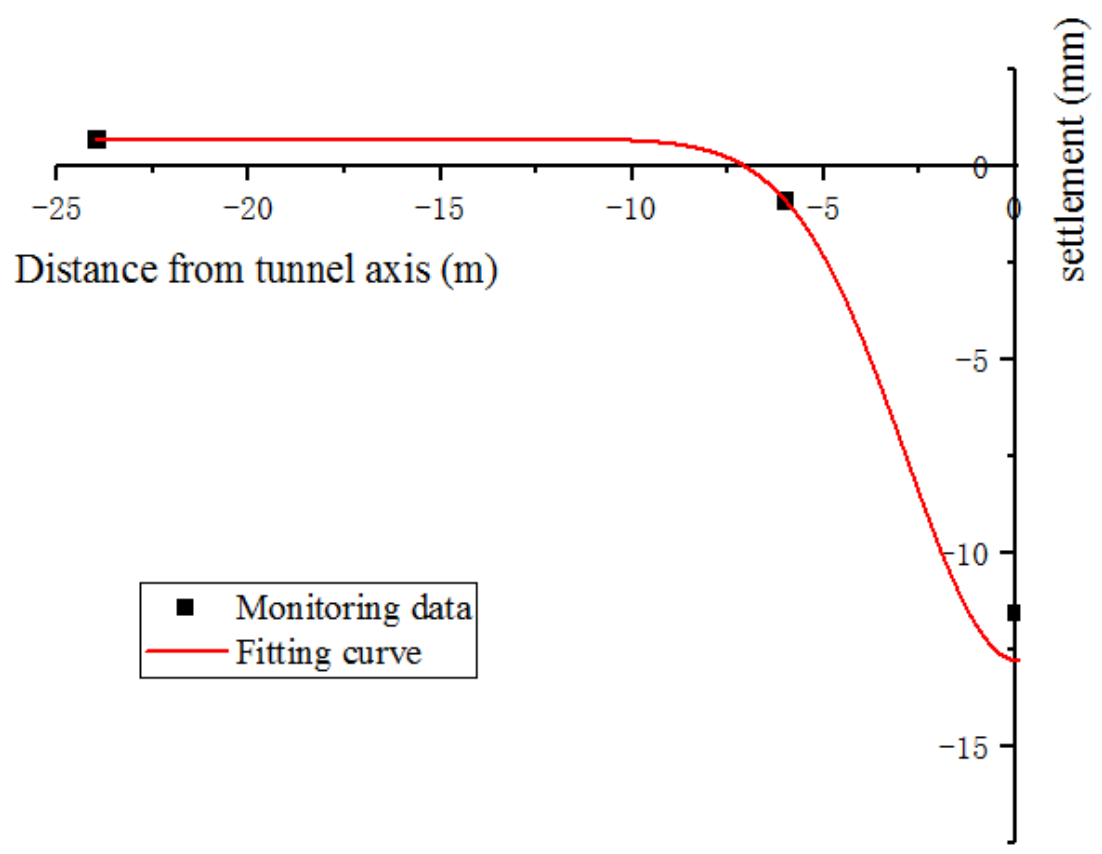

(a) Left surface settlement 


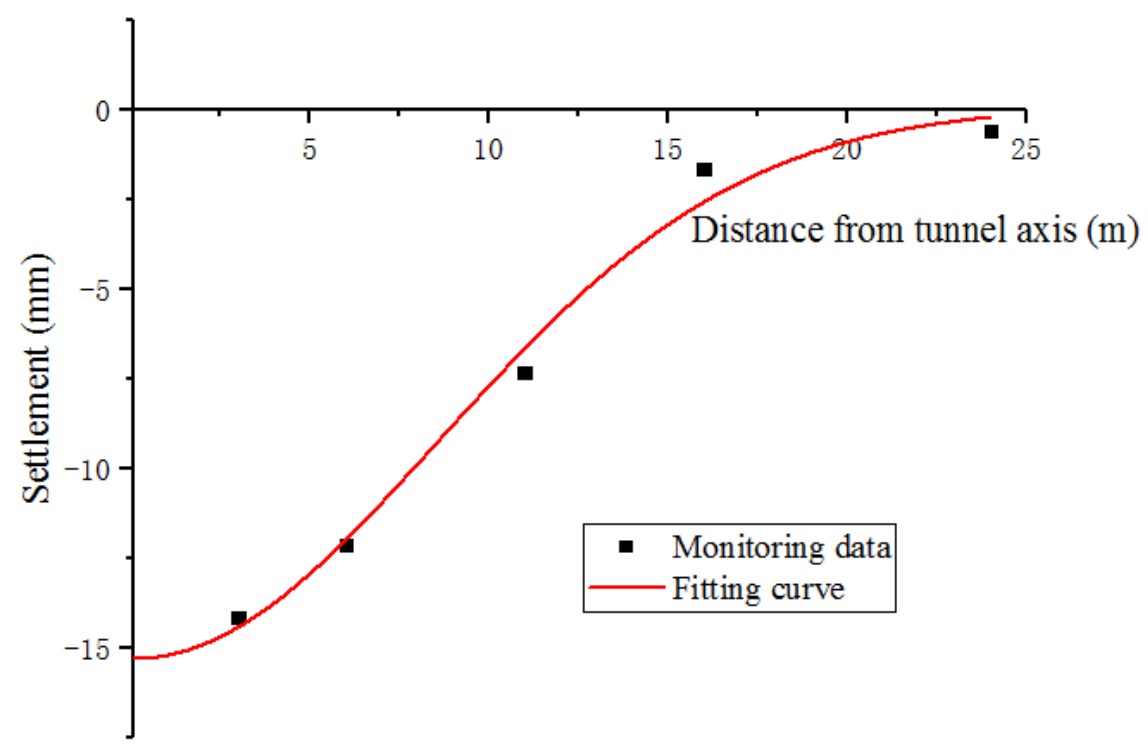

(b) Right surface settlement

Fig.10 Monitoring data and fitting curve

It can be seen from Figure 10 that the laws of the actual surface settlement are the same as the test result: the settlement curve is asymmetrical and the outer side of the tunnel uplifts. So the test results are reliable. Moreover, it is feasible that using piecewise Gaussian curve to describe the surface settlement caused by curving tunnel excavation. However, the values of settlement at the point of $x=x_{c}$ in Figure 10 (a) and (b) are different, so defining the elongation as the $x_{c}$ is not accurate.

The parameters of the fitting curve in the Figure 10 are shown in Table 8.

Table 8 Parameters of the fitting curve

\begin{tabular}{ccc}
\hline$S_{\max }[\mathrm{mm}]$ & $i_{1}[\mathrm{~m}]$ & $i_{2}[\mathrm{~m}]$ \\
\hline 14.42 & 2.95 & 8.48
\end{tabular}

Because the turning radius of this section is $250 \mathrm{~m}$, comparing the test results of the condition of $\mathrm{R}=250 \mathrm{~m}$ in Table 6 with the actual results in Table 8 , it can be found that the maximum settlement and width coefficient of the actual project are larger than that of the test result. On the one hand, it is because the difference of the soil, in the actual project, the soil layer is not uniform sand layer. On the other hand, it is because the copy cutting extend the range of overbreak, which leads to the increase of interspaces of shield tail.

\section{Conclusions}

According to the test results, the characteristics of surface settlement caused by small radius 
tunnel excavation are summarized, and the effects of turning radius and buried depth on the surface settlement are demonstrated. A method to forecast the surface settlement caused by construction of shield tunnel with small curvature radius is developed.

(1) The settlement curve is asymmetrical, which is different with the Peck formula. The point of maximum settlement is not right above the tunnel axis, but move to the inner side of the tunnels, and ground heave is obvious on the outer side of the tunnel, while there is no significant change on the inner side of tunnel. In addition, settlement on the outer side of the tunnel develops more rapidly than the inner side.

(2) As the turning radius decreases, the offset of the settlement trough axis and the value of maximum settlement and uplift increase. Moreover, the ground settlement caused by excavation decreases with the increase of the tunnel burial depth, while the width of settlement trough increases.

(3) The shape of the settlement trough can be described by a piecewise Gaussian curve. So the piecewise Gaussian curve can be used to achieve the prediction of surface settlement caused by shield excavation with small turning radius. And the parameters of the curve are related to the local geological conditions and engineering situation, this is the same as Peck formula. In addition, how to determine the axis of settlement trough still need to be studied.

(4) The test results are compared with the actual monitoring data, though there is difference between the value of the test results and the monitoring data, the laws of surface settlement are the same as the conclusion 1.

\section{Author contribution statement}

Ping Xu: Investigation - editing, supervision and checking. Danhui Xi: Writing, editing - data analysis and original drafts.

\section{Data Availability}

The data supporting the results of this study can be obtained from the corresponding author upon reasonable request.

\section{Conflicts of Interest}

The authors declare that there is no conflict of interest regarding the publication of this paper.

\section{Funding Statement}


The research is funded by National Natural Science Foundation of China (No. 51278467) and

Henan Provincial Science and Technology Research Project (No. 162102210019 ).

\section{References}

Attewell, P.B.; Hurrell M.R. (1985) Settlement development caused by tunneling in soil. Ground Engineering. 18(8),17-20.

Chen C.L.; Zhao C.L.; Wei G., et al. (2014) Prediction of soil settlement induced by double-line shield tunnel based on Peck formula. Rock and Soil Mechanics 35(08): 2212 - 2218.

Ding Z, Wei X W X, Wei G W G. (2017) Prediction methods on tunnel-excavation induced surface settlement around adjacent building. Geomechanics and Engineering (No.2):185-195.

Ding, Z., Wei, X., Zhang, X. and Yin, X. (2019) Analysis of the field monitoring data on soil movements and adjacent building settlement due to shield tunnelling. Engineering Computations, Vol. 36 No. 4, pp. 1219-1237.

Fang E.Q.; Yang L.Z.; Li P.F. (2015) Prediction of ground settlement induced by metro shield construction based on the modified Peck formula. Modern Tunnelling Technology 52(01): 143 -149 .

Gong, Y.F., et al. (2018) Surface subsidence law of double-line shield tunnel based on Peck formula. Journal of Jilin University (Engineering and Technology Edition) (No.5): p. 1411-1417.

Han X.; Li N.; Standing J. R. (2007) An adaptability study of Gaussian equation applied to predicting ground settlements induced by tunneling in China. Rock and Soil Mechanics 28(01): 23 - 28.

Jin D.L.; Li X.G. (2015) Model test of the relationship between the face support pressure and ground surface deformation of a shield-driven tunnel in sand stratum. Modern Tunnelling Technology 52(2):44-51.

Li W.P.; Li X.; Xue Y.D. et al. (2018) Model tests on face stability of shallow shield tunnels in sandy cobble strata. Chinese Journal of Geotechnical Engineering 40(z2):199-203.

Lu L.H.; Sun J.C.; Zhou G.F. et al. (2018) Research on the Surface Deformation Prediction for Curved Shield Construction in Clay Stratum. Journal of Railway Engineering Society 35(5):99105.

O'Reilly, M.P. and New B.M. (1982) Settlements above tunnels in the United Kingdom - Their magnitude and prediction. Pro-ceeding of the Tunnelling 82. Institution of Mining and Metallurgy, London, 173-181.

Peck, R.B. (1969) Deep Excavations and Tunneling in Soft Ground. Proceedings of 7th International Conference on Soil Mechanics and Foundation Engineering, Mexico City, 225-290.

Sigl, O. and G. Atzl (1999) Design of bored tunnel linings for Singapore MRT North East Line C706. Tunnelling and Underground Space Technology 14(4): p. 481 - 490.

Sun X.H.; Miao L.C.; Lin H.S. (2017) Arching effect of soil ahead of working face in shield tunnel in sand with various depths. Rock and Soil Mechanics 38(10):2980-2988. 
Tao L.M.; Chen Z.T.; Wang Y.H. et al. (2018) Model tests of the relationship between ground loss and surface settlement caused by shield tunnel-ling in sand Soils. Modern Tunnelling Technology 55(z2):369-374.

Wang F.; Miao L.C; Wang Z.X. et al. (2014) Study of distribution characteristics of subsurface settlement caused by tunnel construction in sandy soil with model test. Chinese Journal of Rock Mechanics and Engineering 33(S1):3327-3332.

Wang H.T.; Jin H.; Tu B.X., et al. (2017) Model test study on influence of ground settlement caused by shield tunnel construction in sand stratum. China Railway Science 38(006):70-78.

Wang X.R.; Jiang H.J.; Zhu K. et al. (2019) Research on ground settlement laws of urban subway tunnel construction process based on earth pressure shield. Editorial Committee of Earth Science-Journal of China University of Geosciences 44(12):4293-4298.

Zhu H.H.; Xu Q.W.; Fu D.m., et al. (2006) Study on design principle of shield machine applicable to different strata. Rock and Soil Mechanics 27(09):1437-1441.

Zhu Y.T.; Zhang H.; Zhang Z.X.; et al. (2016) Physical model test study of influence of advance of shield tunnel on adjacent underground pipelines. Rock and Soil Mechanics 37(S2): 151-160.

Corresponding author: Xu Ping

Email: plian127@163.com

TEL: +86 13733189057

Address: School of Water and Environment of Zhengzhou University, Kexue Road 100\#, Zhengzhou, Henan Province P.R. China

Zip code: 450001 
Figures

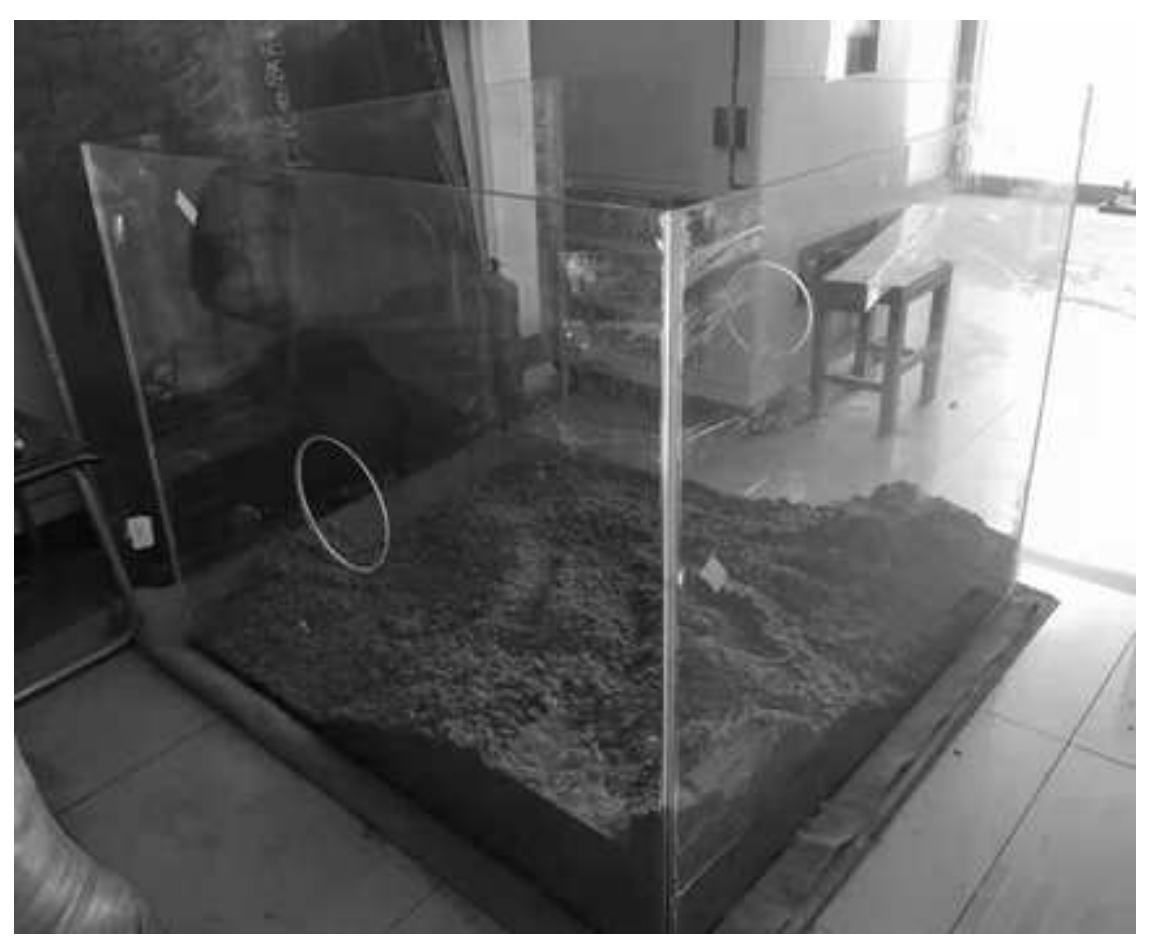

\section{Figure 1}

Model test chamber

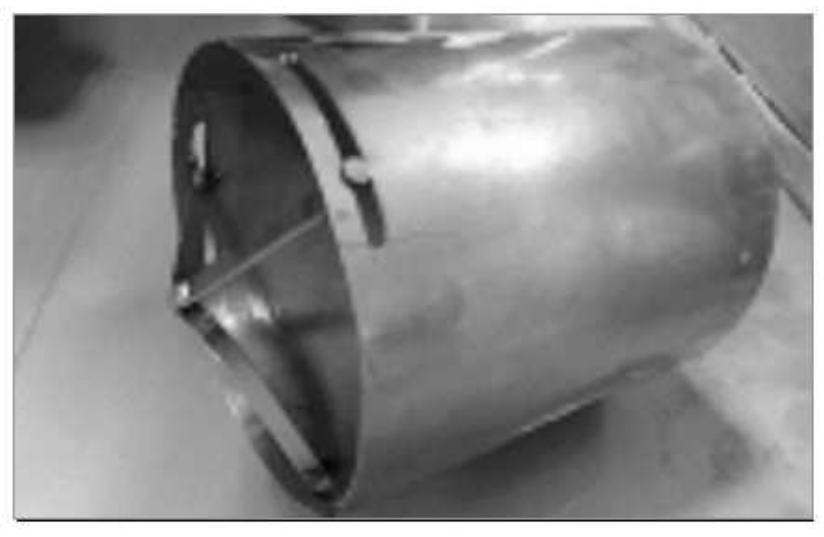

(a) Shield machine model

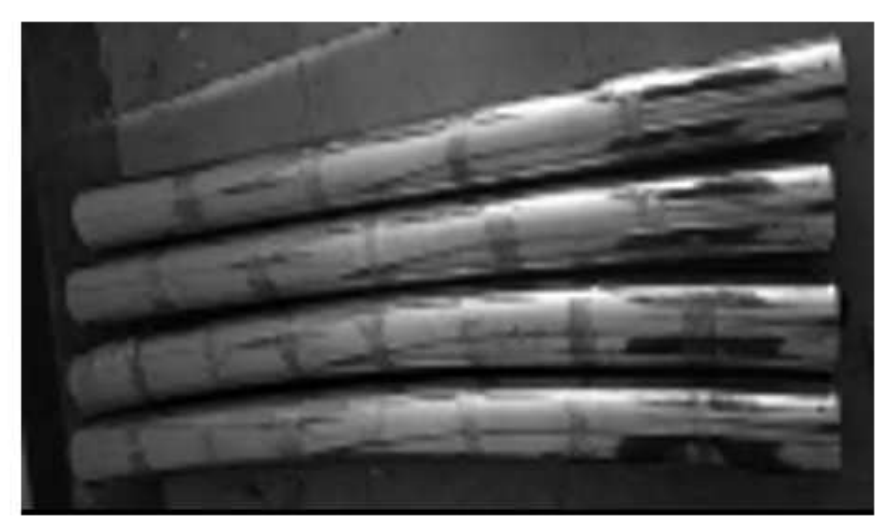

(b) Segment model

Figure 2

Shield machine and segment models 


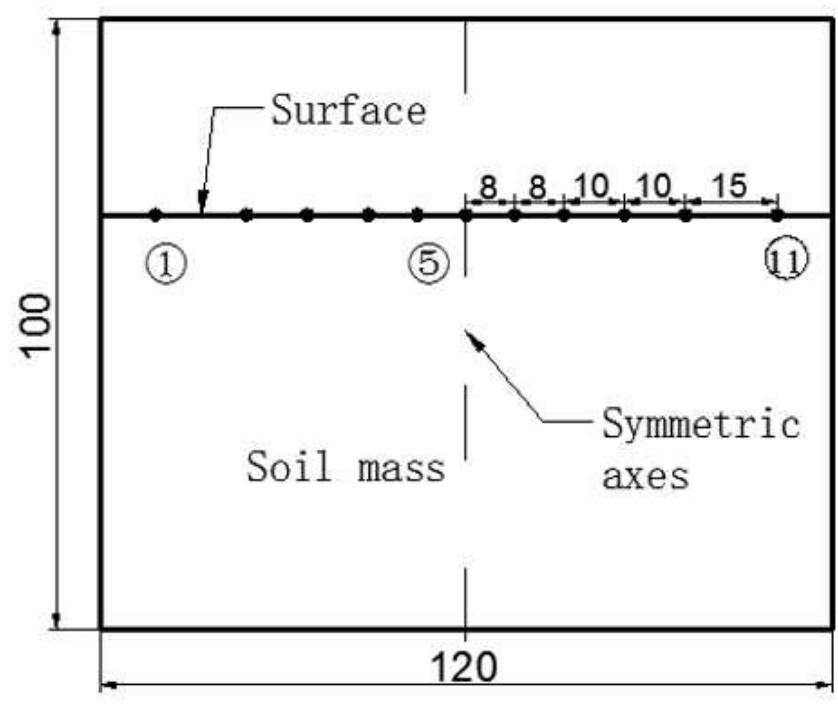

(a) Front view

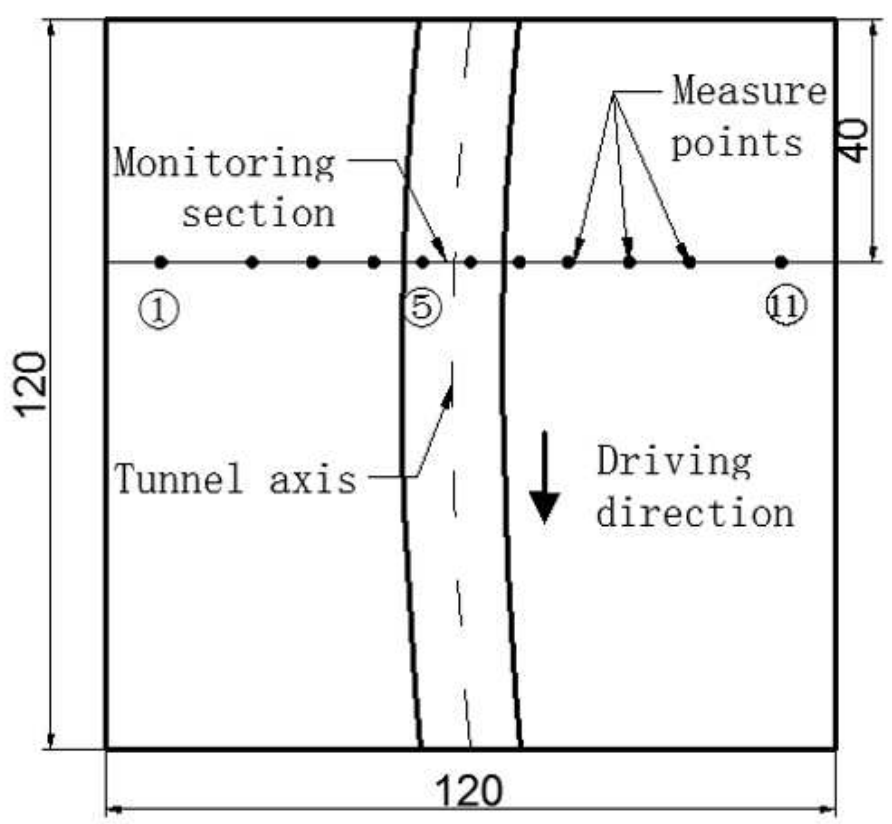

(b) Top view

Figure 3

Sketch of observation points arrangement (unit: $\mathrm{cm}$ ) 


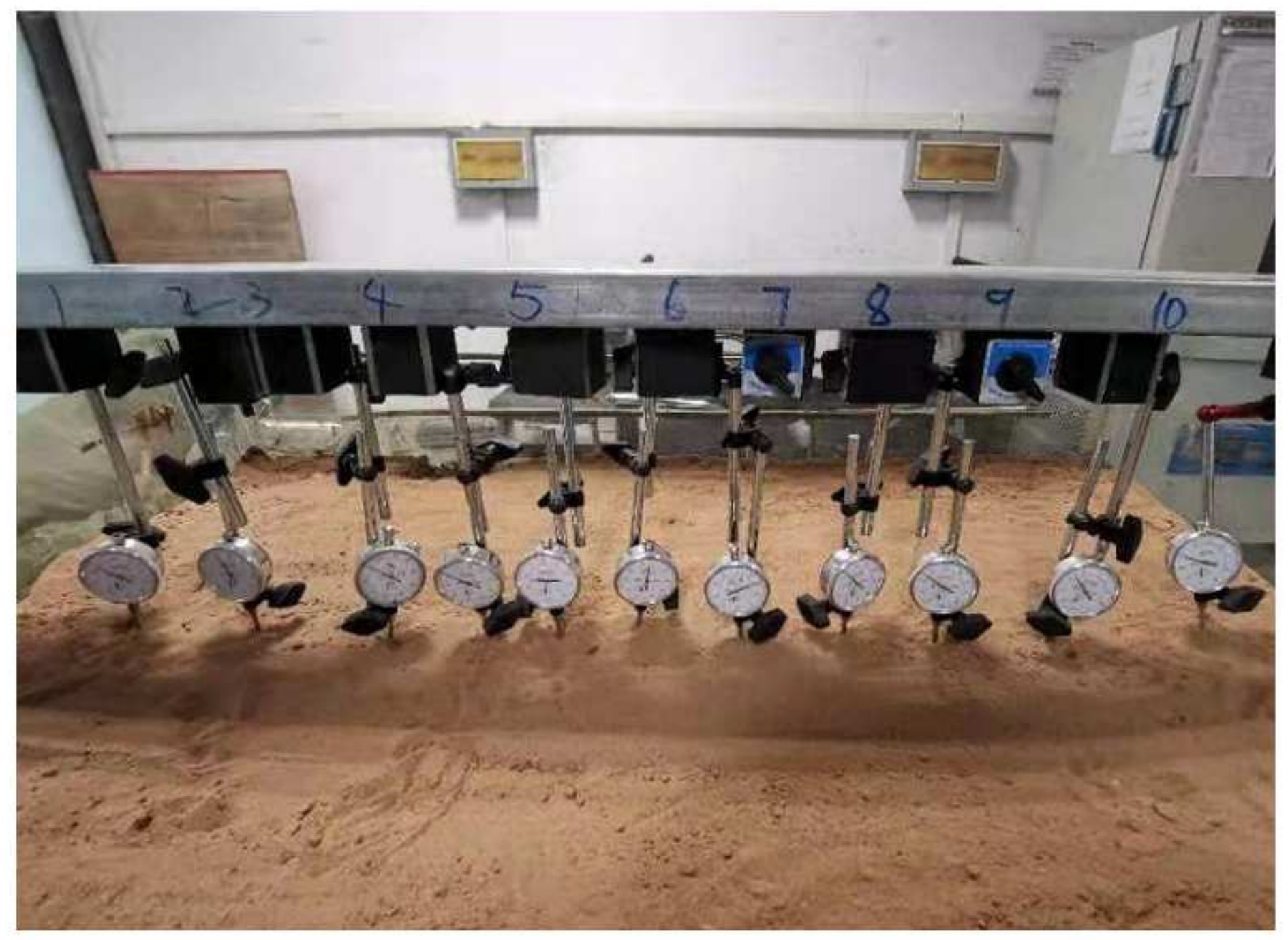

Figure 4

Installation of dial gauges. 


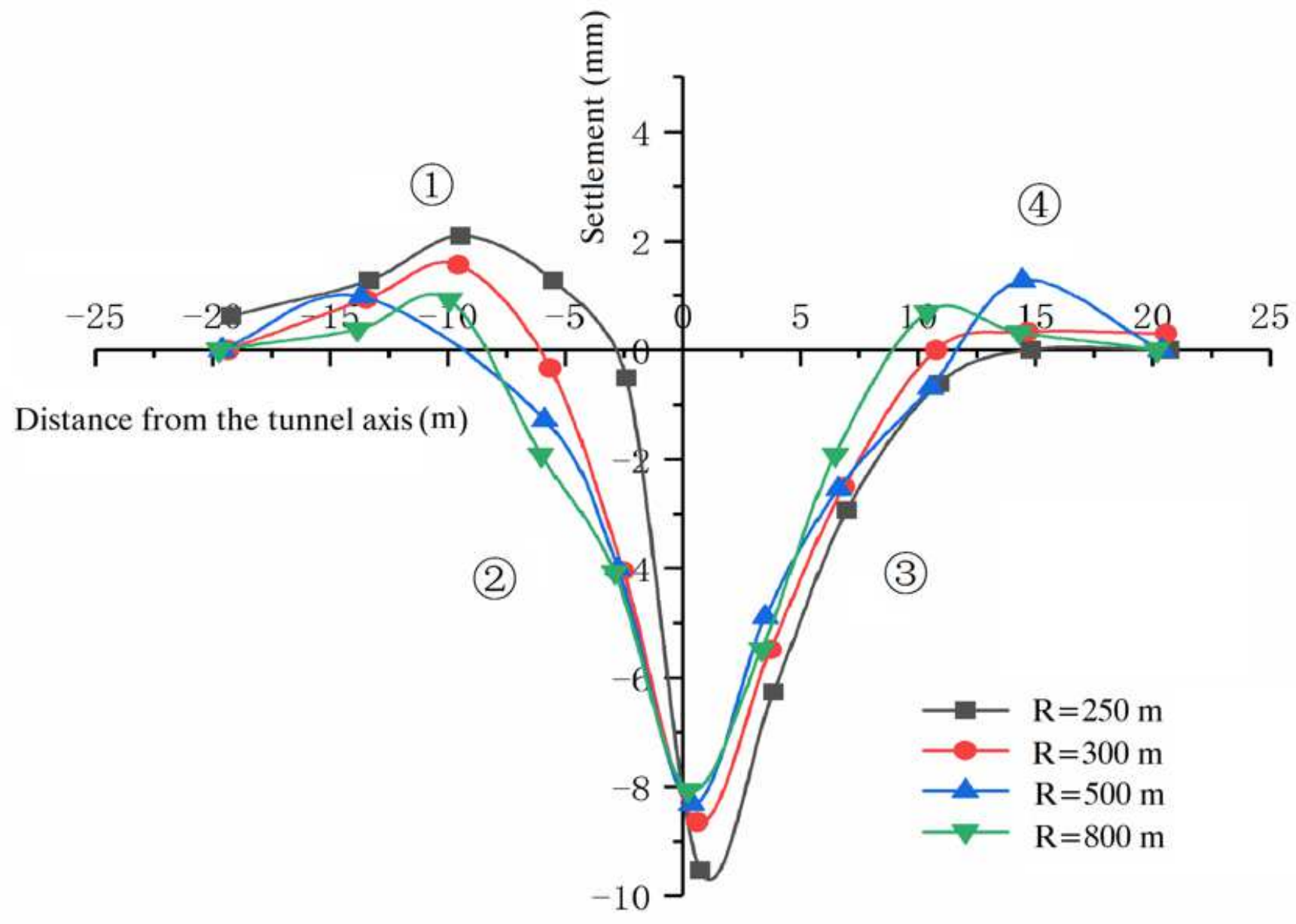

Figure 5

Test results of surface settlement with different turning radius (The $\mathrm{R}$ means the turning radius) 


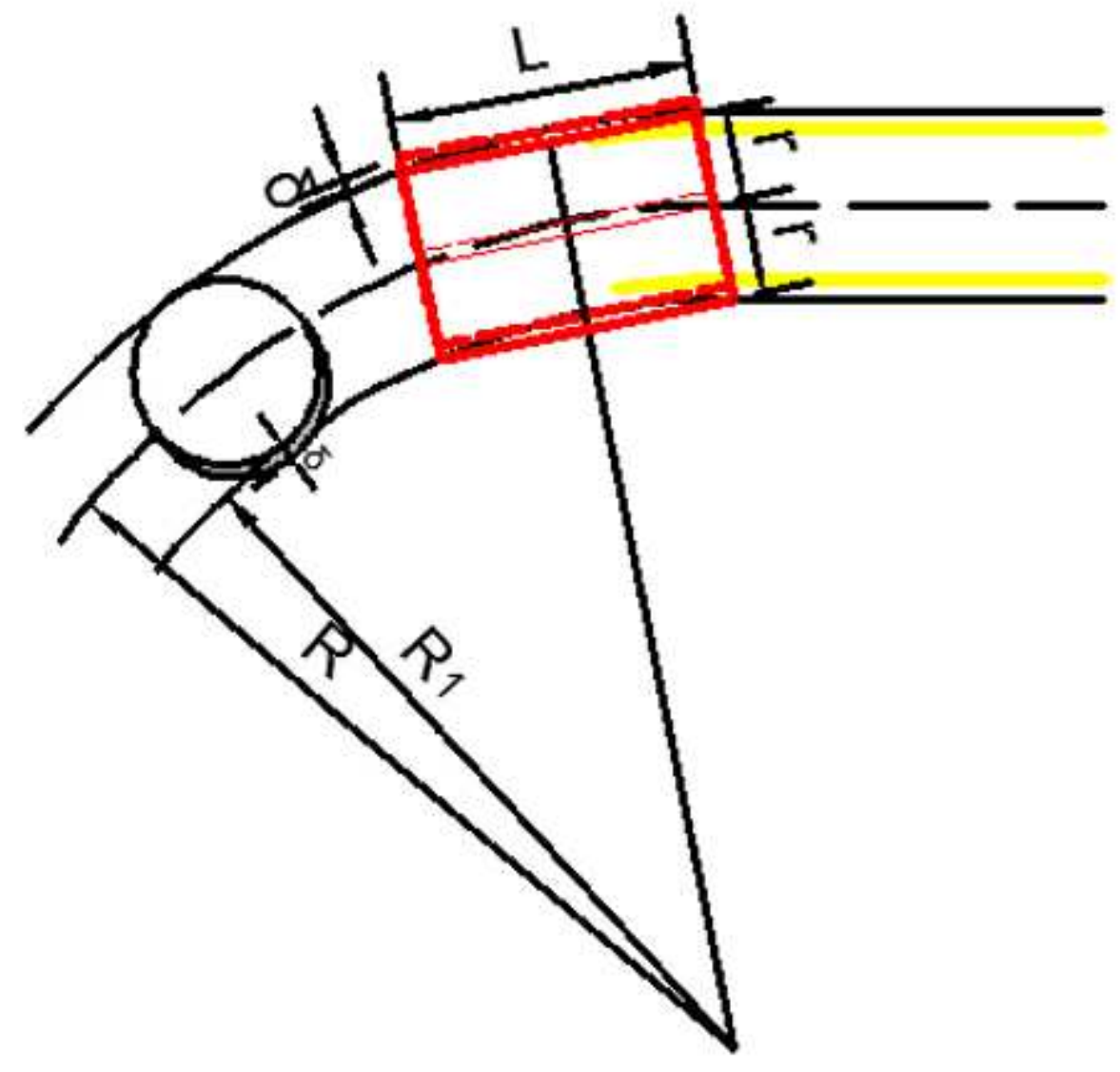

Figure 6

Situation for curvature loss

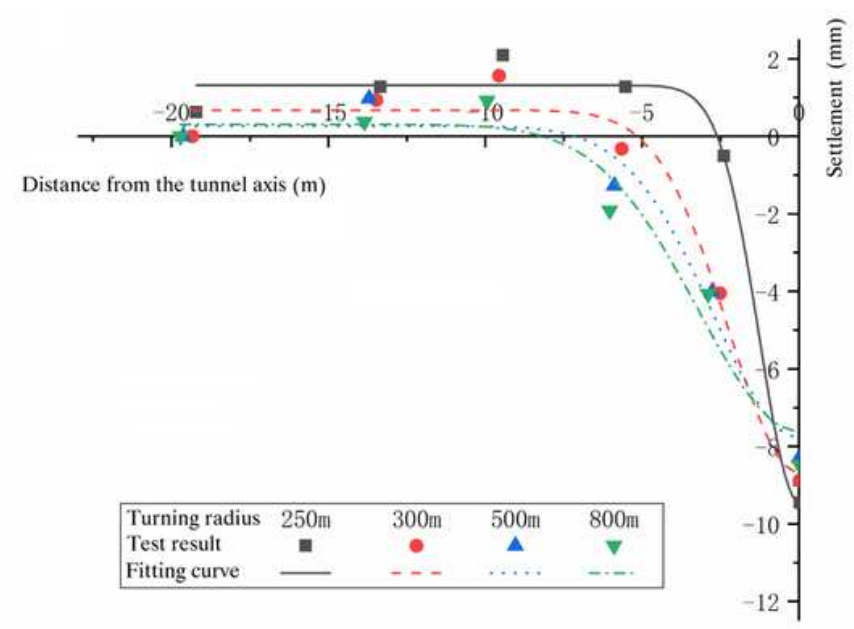

(a) Fitting curves of left side

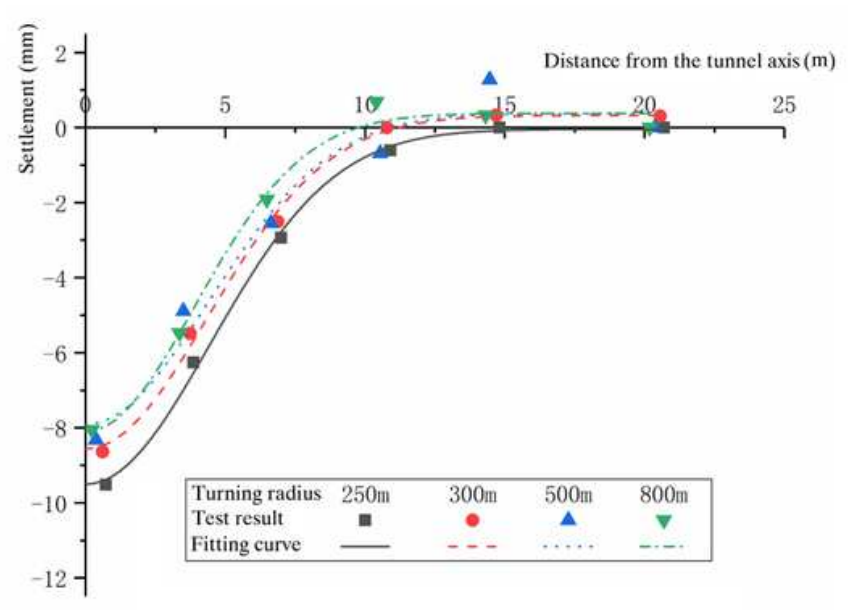

(b) Fitting curves of right side

Figure 7

Piecewise fitted curves by Gaussian equation 


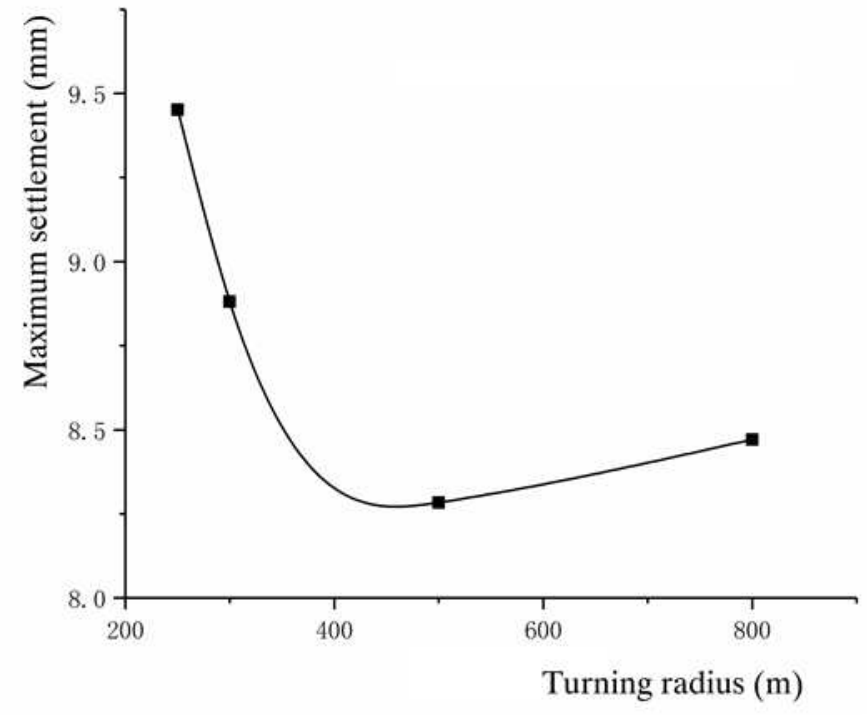

(a) Maximum settlement

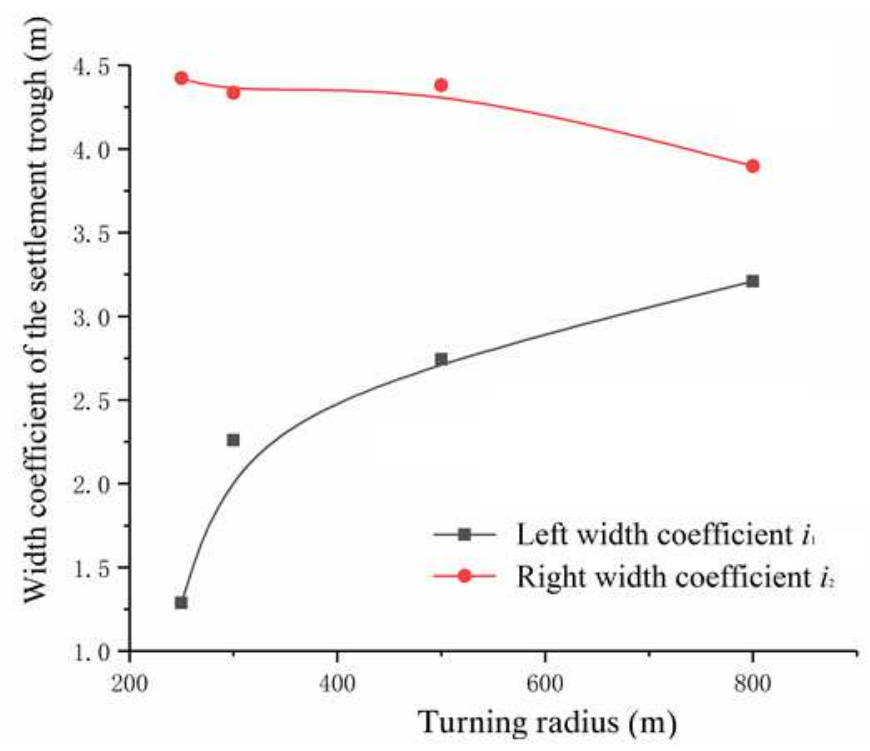

(b) Width coefficient of the settlement trough

\section{Figure 8}

Relation curves between settlement curve parameters and turning radius 


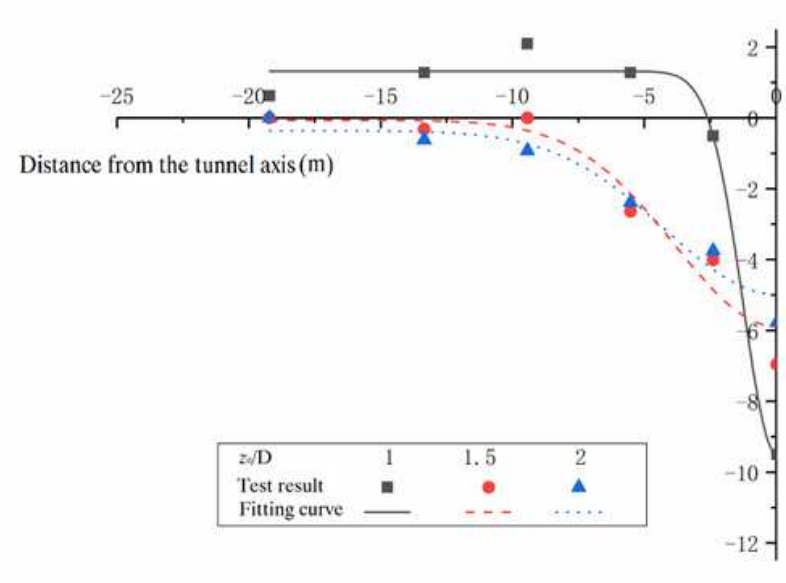

(a) Left surface settlement curve of group 1

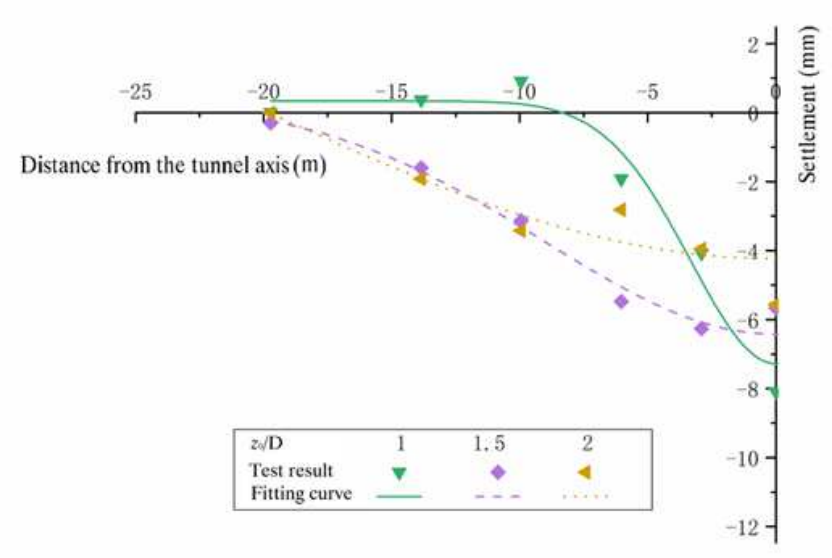

(c) Left surface settlement curve of group 2

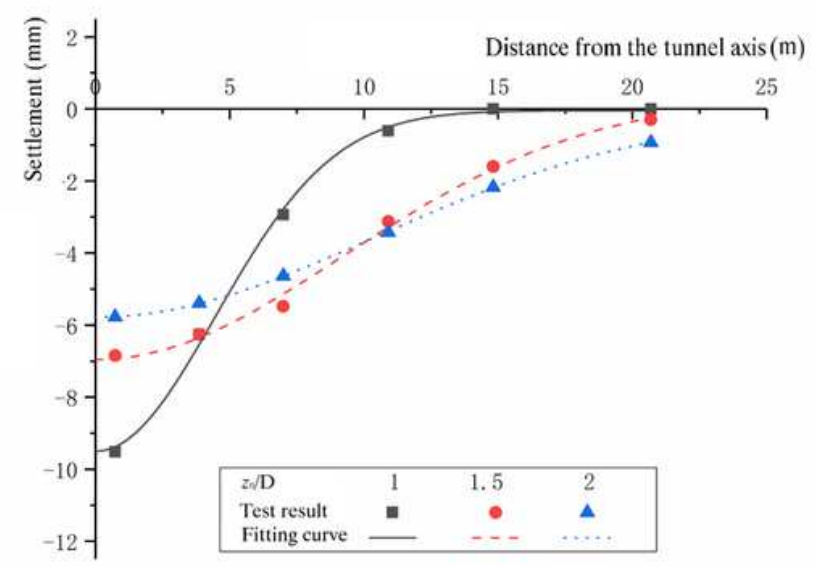

(b) Right surface settlement curve of group 1

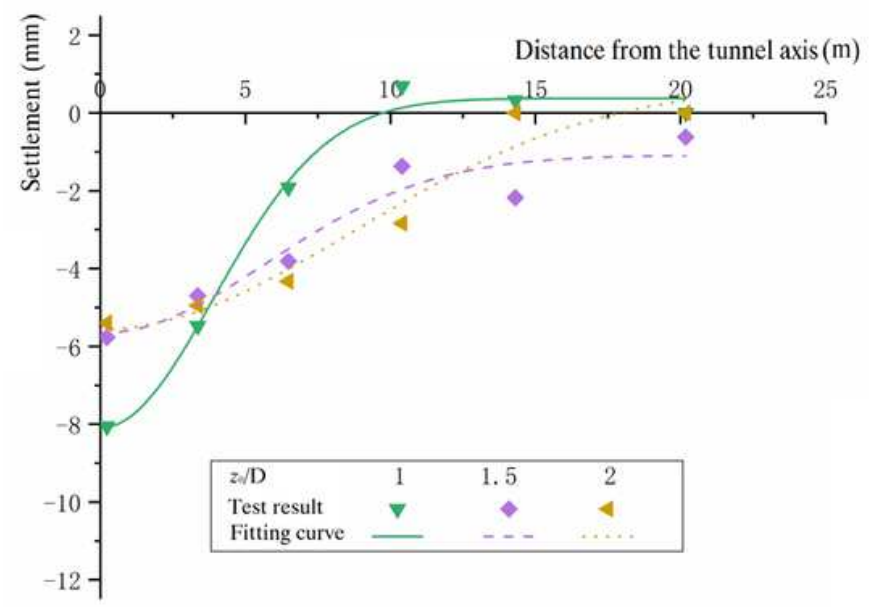

(d) Right surface settlement curve of group 2

\section{Figure 9}




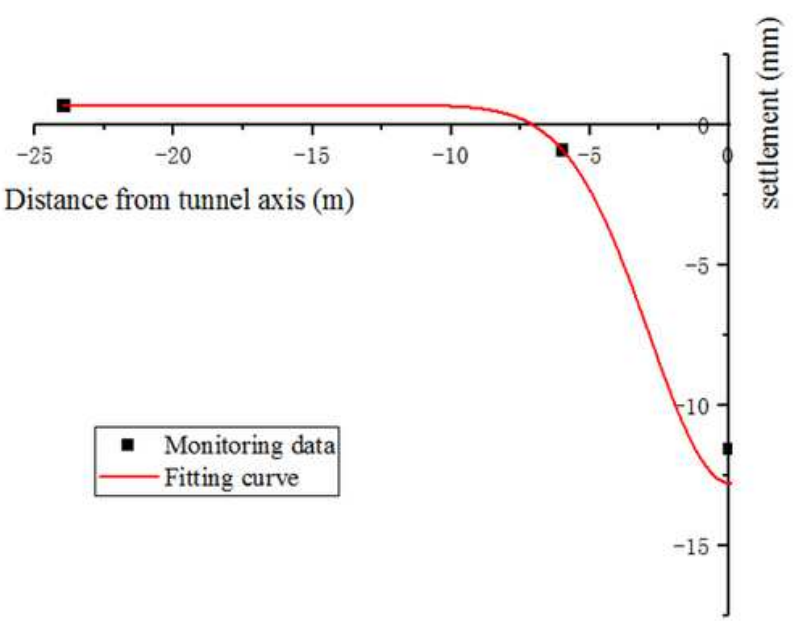

(a) Left surface settlement

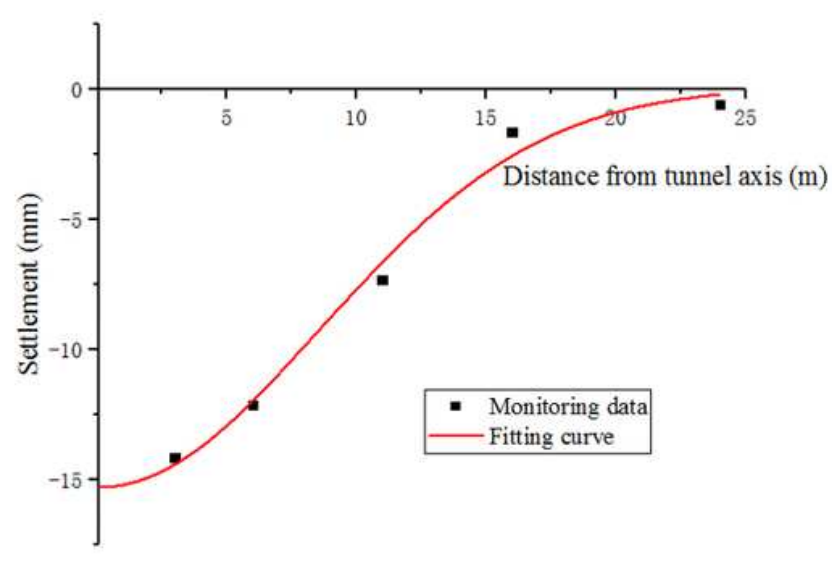

(b) Right surface settlement

Figure 10

Monitoring data and fitting curve 